\title{
Topological coincidence principles
}

\begin{abstract}
Mohamed Jleli ${ }^{\mathrm{a}}$, Donal O'Regan ${ }^{\mathrm{b}, *}$, Bessem Samet $^{\mathrm{a}}$
${ }^{a}$ Department of Mathematics, College of Science, King Saud University, P. O. Box 2455, Riyadh, 11451, Saudi Arabia.

${ }^{b}$ School of Mathematics, Statistics and Applied Mathematics, National University of Ireland, Galway, Ireland.
\end{abstract}

Communicated by Y. J. Cho

\begin{abstract}
In this paper a number of general coincidence principles are presented for set valued maps defined on subsets of completely regular topological spaces.
\end{abstract}

Keywords: Coincidence points, continuation methods, essential maps, extendability.

2010 MSC: 54H25, 47H10.

(C)2018 All rights reserved.

\section{Introduction}

In this paper we present coincidence principles for multimaps. We present two approaches. The first approach is based on the new notion of $\Phi$-essential and $d-\Phi$-essential maps (see $[1,3-5])$ and the second approach is based on the notion of extendability (see [2]). The arguments presented are based on a Urysohn type lemma and homotopy type arguments.

\section{Continuation principles}

Let $E$ be a completely regular topological space and $U$ an open subset of $E$.

We consider classes A and $\mathbf{B}$ of maps.

Definition 2.1. We say $F \in A(\bar{U}, E)$ (respectively $F \in B(\bar{U}, E)$ ) if $F: \bar{U} \rightarrow 2^{E}$ and $F \in A(\bar{U}, E)$ (respectively $F \in \mathbf{B}(\bar{U}, E))$; here $2^{E}$ denotes the family of nonempty subsets of $E$.

In this section we fix a $\Phi \in \mathrm{B}(\overline{\mathrm{U}}, \mathrm{E})$.

Definition 2.2. We say $F \in A_{\partial u}(\bar{U}, E)$ if $F \in A(\bar{U}, E)$ with $F(x) \cap \Phi(x)=\emptyset$ for $x \in \partial U$; here $\partial U$ denotes the boundary of $U$ in $E$.

\footnotetext{
*Corresponding author

Email addresses: jleli@ksu.edu.sa (Mohamed Jleli), donal .oregan@nuigalway.ie (Donal O’Regan), bsamet@ksu.edu.sa (Bessem Samet)
}

doi: $10.22436 /$ jnsa.011.02.11

Received: 2016-01-24 Revised: 2017-06-12 Accepted: 2017-06-12 
Definition 2.3. Let $E$ be a completely regular (respectively normal) topological space, and $U$ an open subset of $E$. Let $F, G \in A_{\partial u}(\bar{U}, E)$. We say $F \cong G$ in $A_{\partial u}(\bar{U}, E)$ if there exists a map $H: \bar{U} \times[0,1] \rightarrow 2^{E}$ with $H(., \eta().) \in A(\bar{U}, E)$ for any continuous function $\eta: \bar{U} \rightarrow[0,1]$ with $\eta(\partial U)=0, H_{t}(x) \cap \Phi(x)=\emptyset$ for any $x \in \partial U$ and $t \in[0,1], H_{1}=F, H_{0}=G$ and $\{x \in \bar{U}: \Phi(x) \cap H(x, t) \neq \emptyset$ for some $t \in[0,1]\}$ is compact (respectively closed); here $H_{t}(x)=H(x, t)$.

Definition 2.4. Let $F \in A_{\partial u}(\bar{U}, E)$. We say $F: \bar{U} \rightarrow 2^{E}$ is $\Phi$-essential in $A_{\partial u}(\bar{U}, E)$ if for every map $\mathrm{J} \in \mathrm{A}_{\partial \mathrm{u}}(\overline{\mathrm{U}}, \mathrm{E})$ with $\left.\mathrm{J}\right|_{\partial \mathrm{u}}=\left.\mathrm{F}\right|_{\partial \mathrm{u}}$ and $\mathrm{J} \cong \mathrm{F}$ in $A_{\partial \mathrm{u}}(\overline{\mathrm{U}}, \mathrm{E})$ there exists $x \in \mathrm{U}$ with $\mathrm{J}(\mathrm{x}) \cap \Phi(\mathrm{x}) \neq \emptyset$.

Theorem 2.5. Let $\mathrm{E}$ be a completely regular (respectively normal) topological space, $\mathrm{U}$ an open subset of $\mathrm{E}$, and let $\mathrm{F} \in \mathrm{A}_{\partial \mathrm{u}}(\overline{\mathrm{U}}, \mathrm{E})$ be $\Phi$-essential in $\mathrm{A}_{\partial \mathrm{u}}(\overline{\mathrm{U}}, \mathrm{E})$. Suppose there exists a map $\mathrm{H}: \overline{\mathrm{U}} \times[0,1] \rightarrow 2^{\mathrm{E}}$ with $\mathrm{H}(., \eta().) \in$ $\mathrm{A}(\overline{\mathrm{U}}, \mathrm{E})$ for any continuous function $\eta: \overline{\mathrm{U}} \rightarrow[0,1]$ with $\eta(\partial \mathrm{U})=0, \Phi(\mathrm{x}) \cap \mathrm{H}_{\mathrm{t}}(\mathrm{x})=\emptyset$ for any $\mathrm{x} \in$ du and $\mathrm{t} \in(0,1], \mathrm{H}_{0}=\mathrm{F}$, and $\{\mathrm{x} \in \overline{\mathrm{U}}: \Phi(\mathrm{x}) \cap \mathrm{H}(\mathrm{x}, \mathrm{t}) \neq \emptyset$ for some $\mathrm{t} \in[0,1]\}$ is compact (respectively closed). In addition assume

$$
\left\{\begin{array}{l}
\text { if } \mu: \overline{\mathrm{U}} \rightarrow[0,1] \text { is any continuous map with } \mu(\partial \mathrm{U})=0 \text {, then } \\
\{x \in \overline{\mathrm{U}}: \emptyset \neq \Phi(x) \cap \mathrm{H}(x, \mathrm{t} \mu(\mathrm{x})) \text { for some } \mathrm{t} \in[0,1]\} \text { is closed. }
\end{array}\right.
$$

Then there exists $\mathrm{x} \in \mathrm{U}$ with $\Phi(x) \cap \mathrm{H}_{1}(\mathrm{x}) \neq \emptyset$; here $\mathrm{H}_{\mathrm{t}}(\mathrm{x})=\mathrm{H}(\mathrm{x}, \mathrm{t})$.

Proof. Let

$$
\mathrm{D}=\{x \in \overline{\mathrm{U}}: \Phi(x) \cap \mathrm{H}(\mathrm{x}, \mathrm{t}) \neq \emptyset \text { for some } \mathrm{t} \in[0,1]\} .
$$

Notice $D \neq \emptyset$ since $F$ is $\Phi$-essential in $A_{\partial u}(\bar{U}, E)$ (note from $(2.1)$ that $F \cong F$ in $A_{\partial u}(\bar{U}, E)$ ). Also $D$ is compact (respectively closed) if $E$ is a completely regular (respectively normal) topological space. Note $\mathrm{D} \cap \partial \mathrm{U}=\emptyset$ (note $\mathrm{H}_{0}=\mathrm{F}$ so for $\mathrm{t}=0$ we have $\Phi(x) \cap \mathrm{H}_{0}(\mathrm{x})=\emptyset$ for $\mathrm{x} \in \partial \mathrm{U}$ since $\mathrm{F} \in A_{\partial \mathrm{u}}(\overline{\mathrm{U}}, \mathrm{E})$ ). Thus there exists a continuous map $\mu: \overline{\mathrm{U}} \rightarrow[0,1]$ with $\mu(\partial \mathrm{U})=0$ and $\mu(\mathrm{D})=1$. Define $\mathrm{J}: \overline{\mathrm{U}} \rightarrow 2^{\mathrm{E}}$ by $J(x)=H(x, \mu(x))$. Note $J \in A_{\partial u}(\bar{U}, E)$ with $\left.J\right|_{\partial u}=\left.F\right|_{\partial u}$ (note if $x \in \partial U$ then $J(x)=H_{0}(x)=F(x)$ and $\mathrm{J}(\mathrm{x}) \cap \Phi(\mathrm{x})=\mathrm{F}(\mathrm{x}) \cap \Phi(\mathrm{x})=\emptyset)$. We now claim

$$
\mathrm{J} \cong \mathrm{F} \text { in } A_{\partial u}(\overline{\mathrm{U}}, \mathrm{E}) .
$$

If the claim is true then since $F$ is $\Phi$-essential in $A_{\partial u}(\bar{U}, E)$ then there exists a $x \in U$ with $J(x) \cap \Phi(x) \neq \emptyset$ (i.e., $\left.H_{\mu(x)}(x) \cap \Phi(x) \neq \emptyset\right)$, and thus $x \in D$ so $\mu(x)=1$ and as a result $H_{1}(x) \cap \Phi(x) \neq \emptyset$.

It remains to show (2.2). Let $\mathrm{Q}: \overline{\mathrm{U}} \times[0,1] \rightarrow 2^{\mathrm{E}}$ be given by $\mathrm{Q}(x, \mathrm{t})=\mathrm{H}(\mathrm{x}, \mathrm{t} \mu(x))$. Note $\mathrm{Q}(., \eta().) \in$ $A(\bar{U}, E)$ for any continuous function $\eta: \bar{U} \rightarrow[0,1]$ with $\eta(\partial U)=0$ and (see (2.1) and Definition 2.3)

$$
\{x \in \overline{\mathrm{U}}: \emptyset \neq \Phi(x) \cap \mathrm{Q}(\mathrm{x}, \mathrm{t})=\Phi(\mathrm{x}) \cap \mathrm{H}(\mathrm{x}, \mathrm{t} \mu(\mathrm{x})) \text { for some } \mathrm{t} \in[0,1]\}
$$

is compact (respectively closed). Note $\mathrm{Q}_{0}=\mathrm{F}$ and $\mathrm{Q}_{1}=\mathrm{J}$. Finally if there exists a $\mathrm{t} \in[0,1]$ and $\mathrm{x} \in \partial \mathrm{U}$ with $\Phi(x) \cap Q_{t}(x) \neq \emptyset$ then $\Phi(x) \cap H_{t \mu(x)}(x) \neq \emptyset$ so $x \in D$, and so $\mu(x)=1$, i.e., $\Phi(x) \cap H_{t}(x) \neq \emptyset$, a contradiction. Thus (2.2) holds.

Remark 2.6. Suppose we change Definition 2.4 as follows. Let $F \in A_{\partial u}(\bar{U}, E)$. We say $F: \bar{U} \rightarrow 2^{E}$ is $\Phi$-essential in $A_{\partial u}(\bar{U}, E)$ if for every map $J \in A_{\partial u}(\bar{U}, E)$ with $\left.J\right|_{\partial u}=\left.F\right|_{\partial u}$ there exists $x \in U$ with $J(x) \cap \Phi(x) \neq \emptyset$. The argument above (note (2.2) is not needed) yields the following result. Let $E$ be a completely regular (respectively normal) topological space, $U$ an open subset of $E$ and let $F \in A_{\partial U}(\bar{U}, E)$ be $\Phi$-essential in $A_{\partial u}(\bar{U}, E)$. Suppose there exists a map $H: \bar{U} \times[0,1] \rightarrow 2^{E}$ with $H(., \eta().) \in A(\bar{U}, E)$ for any continuous function $\eta: \bar{U} \rightarrow[0,1]$ with $\eta(\partial U)=0, \Phi(x) \cap H_{t}(x)=\emptyset$ for any $x \in \partial U$ and $t \in(0,1]$, $\mathrm{H}_{0}=\mathrm{F}$ and $\{x \in \overline{\mathrm{U}}: \Phi(\mathrm{x}) \cap \mathrm{H}(\mathrm{x}, \mathrm{t}) \neq \emptyset$ for some $\mathrm{t} \in[0,1]\}$ is compact (respectively closed). Then there exists $x \in U$ with $\Phi(x) \cap H_{1}(x) \neq \emptyset$; here $H_{t}(x)=H(x, t)$.

Again we consider the map $\mathrm{F}: \overline{\mathrm{U}} \rightarrow 2^{\mathrm{E}}$. In our (quite abstract) result we will assume that we have a homotopy extension type property (i.e., a $\mathrm{H}: \mathrm{E} \times[0,1] \rightarrow 2^{\mathrm{E}}$ with $\left.\mathrm{H}_{1}\right|_{\overline{\mathrm{U}}}=\mathrm{F}$ ). 
Definition 2.7. We say $F \in A(E, E)$ if $F: E \rightarrow 2^{E}$ and $F \in A(E, E)$.

Definition 2.8. Let $E$ be a completely regular (respectively normal) topological space. If $F, G \in A(E, E)$, then we say $F \cong G$ in $A(E, E)$ if there exists a map $\Lambda: E \times[0,1] \rightarrow 2^{E}$ with $\Lambda(., \eta().) \in A(E, E)$ for any continuous function $\eta: E \rightarrow[0,1], \Lambda_{1}=G, \Lambda_{0}=F$ (here $\left.\Lambda_{t}(x)=\Lambda(x, t)\right)$ and $\{x \in E: \Phi(x) \cap \Lambda(x, t) \neq$ $\emptyset$ for some $t \in[0,1]\}$ is compact (respectively closed).

We now fix a $\Phi \in B(E, E)$.

Theorem 2.9. Let $\mathrm{E}$ be a completely regular (respectively normal) topological space and $\mathrm{U}$ an open subset of $\mathrm{E}$. Suppose there exists a map $\mathrm{H}: \mathrm{E} \times[0,1] \rightarrow 2^{\mathrm{E}}$ with $\mathrm{H}(., \eta().) \in \mathrm{A}(\mathrm{E}, \mathrm{E})$ for any continuous function $\eta: \mathrm{E} \rightarrow$ $[0,1]$ and with $\Phi(x) \cap \mathrm{H}(\mathrm{x}, 0)=\emptyset$ for $\mathrm{x} \in \mathrm{E} \backslash \mathrm{U}$, and $\Phi(\mathrm{x}) \cap \mathrm{H}_{\mathrm{t}}(\mathrm{x})=\emptyset$ for any $\mathrm{x} \in \partial \mathrm{U}$ and $\mathrm{t} \in[0,1]$, and $\{\mathrm{x} \in \mathrm{E}: \Phi(\mathrm{x}) \cap \mathrm{H}(\mathrm{x}, \mathrm{t}) \neq \emptyset$ for some $\mathrm{t} \in[0,1]\}$ is compact (respectively closed). In addition assume the following hold:

$$
\begin{aligned}
& \text { for any } \mathrm{J} \in \mathrm{A}(\mathrm{E}, \mathrm{E}) \text { with } \mathrm{J} \cong \mathrm{H}_{0} \text { in } \mathrm{A}(\mathrm{E}, \mathrm{E}) \text { there exists } \mathrm{x} \in \mathrm{E} \text { with } \Phi(\mathrm{x}) \cap \mathrm{J}(\mathrm{x}) \neq \emptyset \text {, } \\
& \left\{\mathrm{x} \in \mathrm{E} \backslash \mathrm{U}: \mathrm{H}_{\mathrm{t}}(\mathrm{x}) \cap \Phi(\mathrm{x}) \neq \emptyset \text { for some } \mathrm{t} \in[0,1]\right\} \text { is closed, }
\end{aligned}
$$

and

$$
\left\{\begin{array}{l}
\text { if } \mu: \mathrm{E} \rightarrow[0,1] \text { is any continuous map with } \mu(\overline{\mathrm{U}})=1 \text {, then } \\
\{\mathrm{x} \in \mathrm{E}: \emptyset \neq \Phi(\mathrm{x}) \cap \mathrm{H}(\mathrm{x}, \mathrm{t} \mu(\mathrm{x})) \text { for some } \mathrm{t} \in[0,1]\} \text { is closed. }
\end{array}\right.
$$

Then there exists $\mathrm{x} \in \mathrm{U}$ with $\Phi(\mathrm{x}) \cap \mathrm{H}_{1}(\mathrm{x}) \neq \emptyset$; here $\mathrm{H}_{\mathrm{t}}(\mathrm{x})=\mathrm{H}(\mathrm{x}, \mathrm{t})$.

Proof. Let

$$
\mathrm{D}=\left\{x \in \mathrm{E} \backslash \mathrm{U}: \Phi(x) \cap \mathrm{H}_{\mathrm{t}}(\mathrm{x}) \neq \emptyset \text { for some } \mathrm{t} \in[0,1]\right\} .
$$

We consider two cases, as $\mathrm{D} \neq \emptyset$ and $\mathrm{D}=\emptyset$.

Case (i). $\mathrm{D}=\emptyset$.

Then for every $t \in[0,1]$ we have $\Phi(x) \cap H_{t}(x)=\emptyset$ for $x \in E \backslash U$. Also from $H_{1} \cong H_{0}$ in $A(E, E)$ and (2.3) we know there exists $y \in E$ with $\Phi(y) \cap H_{1}(y) \neq \emptyset$. Since $\Phi(x) \cap H_{1}(x)=\emptyset$ for $x \in E \backslash U$ we deduce that $\mathrm{y} \in \mathrm{U}$, and we are finished.

Case (ii). $\mathrm{D} \neq \emptyset$.

Now (note $H_{1} \cong H_{0}$ in $A(E, E)$ and (2.4)) $D$ is compact (respectively closed) and $D \cap \bar{U} \neq \emptyset$ (since $\Phi(x) \cap H_{t}(x)=\emptyset$ for $x \in \partial U$ and $\left.t \in[0,1]\right)$. Then there exists a continuous map $\mu: E \rightarrow[0,1]$ with $\mu(\mathrm{D})=0$ and $\mu(\overline{\mathrm{U}})=1$. Define a map $\mathrm{R}: \mathrm{E} \rightarrow 2^{\mathrm{E}}$ by

$$
\mathrm{R}(x)=\mathrm{H}(x, \mu(x)) .
$$

Now $R \in A(E, E)$. In fact $R \cong H_{0}$ in $A(E, E)$. To see this let $\Omega: E \times[0,1] \rightarrow 2^{E}$ be given by

$$
\Omega(x, t)=H(x, t \mu(x)) .
$$

Note $\Omega(., \eta().) \in A(E, E)$ for any continuous function $\eta: E \rightarrow[0,1]$, and (note (2.5) and $H_{1} \cong H_{0}$ in $A(E, E)$ ),

$$
\{x \in E: \Phi(x) \cap \Omega(x, t)=\Phi(x) \cap H(x, t \mu(x)) \neq \emptyset \text { for some } t \in[0,1]\}
$$

is compact (respectively closed). Also $\Omega_{1}=\mathrm{R}$ and $\Omega_{0}=\mathrm{H}_{0}$.

Now (2.3) guarantees that there exists $x \in E$ with $\Phi(x) \cap R(x)=\Phi(x) \cap H_{\mu(x)}(x) \neq \emptyset$. If $x \in E \backslash U$ then since $x \in D$ we have $\emptyset \neq \Phi(x) \cap H(x, \mu(x))=\Phi(x) \cap H(x, 0)$, a contradiction. Thus $x \in U$ and so $\emptyset \neq \Phi(x) \cap \mathrm{H}(\mathrm{x}, \mu(\mathrm{x}))=\Phi(\mathrm{x}) \cap \mathrm{H}(\mathrm{x}, 1)$.

Remark 2.10. In Definition 2.8 and in the statement of Theorem 2.9 we could replace, any continuous map $\eta: E \rightarrow[0,1]$, with any continuous map $\eta: E \rightarrow[0,1]$ with $\eta(\bar{U})=1$. 
We now show that the ideas in this section can be applied to other natural situations. Let $E$ be a Hausdorff topological vector space (so automatically a completely regular space), $Y$ a topological vector space, and $U$ an open subset of $E$. Also let $L: \operatorname{dom}(L) \subseteq E \rightarrow Y$ be a linear single valued map; here $\operatorname{dom}(L)$ is a vector subspace of $E$. Finally $T: E \rightarrow Y$ will be a linear single valued map with $L+T: \operatorname{dom}(L) \rightarrow Y$ a bijection; for convenience we say $T \in H_{L}(E, Y)$.

Definition 2.11. We say $F \in A(\bar{U}, Y ; L, T)$ (respectively $F \in B(\bar{U}, Y ; L, T)$ ) if $F: \bar{U} \rightarrow 2^{Y}$ and $(L+T)^{-1}(F+T) \in$ $A(\bar{U}, E)$ (respectively $(L+T)^{-1}(F+T) \in B(\bar{U}, E)$ ).

We now fix a $\Phi \in B(\bar{U}, Y ; L, T)$.

Definition 2.12. We say $F \in A_{\partial u}(\bar{U}, Y ; L, T)$ if $F \in A(\bar{U}, Y ; L, T)$ with $(L+T)^{-1}(F+T)(x) \cap(L+T)^{-1}(\Phi+$ $\mathrm{T})(\mathrm{x})=\emptyset$ for $x \in \partial \mathrm{u}$.

Definition 2.13. Let $F, G \in A_{\partial u}(\bar{U}, Y ; L, T)$. We say $F \cong G$ in $A_{\partial u}(\bar{U}, Y ; L, T)$ if there exists a map $H$ : $\overline{\mathrm{U}} \times[0,1] \rightarrow 2^{\mathrm{Y}}$ with $(\mathrm{L}+\mathrm{T})^{-1}(\mathrm{H}(., \eta())+.\mathrm{T}().) \in \mathrm{A}(\overline{\mathrm{U}}, \mathrm{E})$ for any continuous function $\eta: \overline{\mathrm{U}} \rightarrow[0,1]$ with $\eta(\partial U)=0,(L+T)^{-1}\left(H_{t}+T\right)(x) \cap(L+T)^{-1}(\Phi+T)(x)=\emptyset$ for any $x \in \partial U$ and $t \in[0,1], H_{1}=F, H_{0}=G$ and

$$
\left\{x \in \overline{\mathrm{U}}:(\mathrm{L}+\mathrm{T})^{-1}(\Phi+\mathrm{T})(\mathrm{x}) \cap(\mathrm{L}+\mathrm{T})^{-1}\left(\mathrm{H}_{\mathrm{t}}+\mathrm{T}\right)(\mathrm{x}) \neq \emptyset \text { for some } \mathrm{t} \in[0,1]\right\}
$$

is compact; here $H_{t}(x)=H(x, t)$.

Definition 2.14. Let $F \in A_{\partial u}(\bar{U}, Y ; L, T)$. We say $F$ is $L-\Phi$-essential in $A_{\partial u}(\bar{U}, Y ; L, T)$ if for every map $\mathrm{J} \in \mathrm{A}_{\partial \mathrm{u}}(\overline{\mathrm{U}}, \mathrm{Y} ; \mathrm{L}, \mathrm{T})$ with $\left.\mathrm{J}\right|_{\partial \mathrm{u}}=\left.\mathrm{F}\right|_{\partial \mathrm{u}}$ and $\mathrm{J} \cong \mathrm{F}$ in $A_{\partial \mathrm{u}}(\overline{\mathrm{U}}, \mathrm{Y} ; \mathrm{L}, \mathrm{T})$ there exists $x \in \mathrm{U}$ with $(\mathrm{L}+\mathrm{T})^{-1}(\mathrm{~J}+$ $\mathrm{T})(\mathrm{x}) \cap(\mathrm{L}+\mathrm{T})^{-1}(\Phi+\mathrm{T})(\mathrm{x}) \neq \emptyset$.

Theorem 2.15. Let $\mathrm{E}$ be a topological vector space (so automatically completely regular), $\mathrm{Y}$ a topological vector space, $\mathrm{U}$ an open subset of $\mathrm{E}, \mathrm{L}: \operatorname{dom}(\mathrm{L}) \subseteq \mathrm{E} \rightarrow \mathrm{Y}$ a linear single valued map, and $\mathrm{T} \in \mathrm{H}_{\mathrm{L}}(\mathrm{E}, \mathrm{Y})$. Let $\mathrm{F} \in \mathrm{A}_{\partial \mathrm{u}}(\overline{\mathrm{U}}, \mathrm{Y} ; \mathrm{L}, \mathrm{T})$ be $\mathrm{L}-\Phi$-essential in $\mathrm{A}_{\partial \mathrm{u}}(\overline{\mathrm{U}}, \mathrm{Y} ; \mathrm{L}, \mathrm{T})$. Suppose there exists a map $\mathrm{H}: \overline{\mathrm{U}} \times[0,1] \rightarrow 2^{\mathrm{Y}}$ with $(\mathrm{L}+\mathrm{T})^{-1}(\mathrm{H}(., \eta())+.\mathrm{T}().) \in A(\overline{\mathrm{U}}, \mathrm{E})$ for any continuous function $\eta: \overline{\mathrm{U}} \rightarrow[0,1]$ with $\eta(\partial \mathrm{U})=0,(\mathrm{~L}+$ $\mathrm{T})^{-1}\left(\mathrm{H}_{\mathrm{t}}+\mathrm{T}\right)(\mathrm{x}) \cap(\mathrm{L}+\mathrm{T})^{-1}(\Phi+\mathrm{T})(\mathrm{x})=\emptyset$ for any $\mathrm{x} \in \partial \mathrm{U}$ and $\mathrm{t} \in(0,1], \mathrm{H}_{0}=\mathrm{F}$ (here $\mathrm{H}_{\mathrm{t}}(\mathrm{x})=\mathrm{H}(\mathrm{x}, \mathrm{t})$ ) and $\left\{x \in \overline{\mathrm{U}}:(\mathrm{L}+\mathrm{T})^{-1}(\Phi+\mathrm{T})(\mathrm{x}) \cap(\mathrm{L}+\mathrm{T})^{-1}\left(\mathrm{H}_{\mathrm{t}}+\mathrm{T}\right)(\mathrm{x}) \neq \emptyset\right.$ for some $\left.\mathrm{t} \in[0,1]\right\}$ is compact. In addition assume

$\{$ if $\mu: \overline{\mathrm{U}} \rightarrow[0,1]$ is any continuous map with $\mu(\partial \mathrm{U})=0$, then

$\left\{x \in \overline{\mathrm{U}}:(\mathrm{L}+\mathrm{T})^{-1}(\Phi+\mathrm{T})(\mathrm{x}) \cap(\mathrm{L}+\mathrm{T})^{-1}\left(\mathrm{H}_{\mathrm{t} \mu(\mathrm{x})}+\mathrm{T}\right)(\mathrm{x}) \neq \emptyset\right.$ for some $\left.\mathrm{t} \in[0,1]\right\}$ is closed.

Then there exists $\mathrm{x} \in \mathrm{U}$ with $(\mathrm{L}+\mathrm{T})^{-1}\left(\mathrm{H}_{1}+\mathrm{T}\right)(\mathrm{x}) \cap(\mathrm{L}+\mathrm{T})^{-1}(\Phi+\mathrm{T})(\mathrm{x}) \neq \emptyset$.

Proof. Let

$$
\mathrm{D}=\left\{x \in \overline{\mathrm{U}}:(\mathrm{L}+\mathrm{T})^{-1}(\Phi+\mathrm{T})(\mathrm{x}) \cap(\mathrm{L}+\mathrm{T})^{-1}\left(\mathrm{H}_{\mathrm{t}}+\mathrm{T}\right)(\mathrm{x}) \neq \emptyset \text { for some } \mathrm{t} \in[0,1]\right\} .
$$

Note $D \neq \emptyset$ (note $F$ is $L-\Phi$-essential in $A_{\partial u}(\bar{U}, Y ; L, T)$ ) and $D$ is compact, $D \cap \partial U=\emptyset$ so there exists a continuous map $\mu: \overline{\mathrm{U}} \rightarrow[0,1]$ with $\mu(\partial \mathrm{U})=0$ and $\mu(\mathrm{D})=1$. Define $J: \overline{\mathrm{U}} \rightarrow 2^{\gamma}$ by $J(x)=\mathrm{H}(x, \mu(x))$. Note $\mathrm{J} \in A_{\partial \mathrm{u}}(\overline{\mathrm{U}}, \mathrm{Y} ; \mathrm{L}, \mathrm{T})$ and $\left.\mathrm{J}\right|_{\partial \mathrm{u}}=\left.\mathrm{F}\right|_{\partial u}$. Also note $\mathrm{J} \cong \mathrm{F}$ in $A_{\partial \mathrm{u}}(\overline{\mathrm{U}}, \mathrm{Y} ; \mathrm{L}, \mathrm{T})$ (to see this let $\mathrm{Q}: \overline{\mathrm{U}} \times[0,1] \rightarrow 2^{Y}$ be given by $Q(x, t)=H(x, t \mu(x)))$. Now since $F$ is $L-\Phi$-essential in $A_{\partial u}(\bar{U}, Y ; L, T)$ there exists $x \in U$ with $(\mathrm{L}+\mathrm{T})^{-1}(\mathrm{~J}+\mathrm{T})(\mathrm{x}) \cap(\mathrm{L}+\mathrm{T})^{-1}(\Phi+\mathrm{T})(\mathrm{x}) \neq \emptyset$ (i.e., $\left.(\mathrm{L}+\mathrm{T})^{-1}\left(\mathrm{H}_{\mu(\mathrm{x})}+\mathrm{T}\right)(\mathrm{x}) \cap(\mathrm{L}+\mathrm{T})^{-1}(\Phi+\mathrm{T})(\mathrm{x}) \neq \emptyset\right)$, and thus $x \in D$ so $\mu(x)=1$ and we are finished.

Remark 2.16. Suppose we change Definition 2.14 as follows. Let $F \in A_{\partial u}(\bar{U}, Y ; L, T)$. We say $F$ is $L-\Phi-$ essential in $A_{\partial u}(\bar{U}, Y ; L, T)$ if for every map $J \in A_{\partial u}(\bar{U}, Y ; L, T)$ with $\left.J\right|_{\partial u}=\left.F\right|_{\partial u}$ there exists $x \in U$ with $(L+T)^{-1}(J+T)(x) \cap(L+T)^{-1}(\Phi+T)(x) \neq \emptyset$. The argument above yields the following result. Let $E$ be a topological vector space, $Y$ a topological vector space, $U$ an open subset of $E, L: \operatorname{dom}(L) \subseteq E \rightarrow Y$ a linear single valued map, and $T \in H_{L}(E, Y)$. Let $F \in A_{\partial u}(\bar{U}, Y ; L, T)$ be $L-\Phi$-essential in $A_{\partial u}(\bar{U}, Y ; L, T)$. Suppose there exists a map $\mathrm{H}: \overline{\mathrm{U}} \times[0,1] \rightarrow 2^{\mathrm{Y}}$ with $(\mathrm{L}+\mathrm{T})^{-1}(\mathrm{H}(., \eta())+.T().) \in A(\overline{\mathrm{U}}, \mathrm{E})$ for any continuous 
function $\eta: \overline{\mathrm{U}} \rightarrow[0,1]$ with $\eta(\partial \mathrm{U})=0,(\mathrm{~L}+\mathrm{T})^{-1}\left(\mathrm{H}_{\mathrm{t}}+\mathrm{T}\right)(\mathrm{x}) \cap(\mathrm{L}+\mathrm{T})^{-1}(\Phi+\mathrm{T})(\mathrm{x})=\emptyset$ for any $\mathrm{x} \in \partial \mathrm{U}$ and $\mathrm{t} \in(0,1], \mathrm{H}_{0}=\mathrm{F}$ (here $\left.\mathrm{H}_{\mathrm{t}}(\mathrm{x})=\mathrm{H}(\mathrm{x}, \mathrm{t})\right)$ and $\left\{\mathrm{x} \in \overline{\mathrm{U}}:(\mathrm{L}+\mathrm{T})^{-1}(\Phi+\mathrm{T})(\mathrm{x}) \cap(\mathrm{L}+\mathrm{T})^{-1}\left(\mathrm{H}_{\mathrm{t}}+\mathrm{T}\right)(\mathrm{x}) \neq \emptyset\right.$ for some $t \in[0,1]\}$ is compact. Then there exists $x \in U$ with $(L+T)^{-1}\left(H_{1}+T\right)(x) \cap(L+T)^{-1}(\Phi+T)(x) \neq$ $\emptyset$.

Remark 2.17. If $\mathrm{E}$ is a normal topological vector space then the assumption that $\mathrm{D}$ (in the proof of Theorem 2.15) is compact, can be replaced by D is closed, in the statement (and proof) of Theorem 2.15 and also the assumption that

$$
\left\{x \in \overline{\mathrm{U}}:(\mathrm{L}+\mathrm{T})^{-1}(\Phi+\mathrm{T})(\mathrm{x}) \cap(\mathrm{L}+\mathrm{T})^{-1}\left(\mathrm{H}_{\mathrm{t}}+\mathrm{T}\right)(\mathrm{x}) \neq \emptyset \text { for some } \mathrm{t} \in[0,1]\right\}
$$

is compact, can be replaced by

$$
\left\{x \in \overline{\mathrm{U}}:(\mathrm{L}+\mathrm{T})^{-1}(\Phi+\mathrm{T})(\mathrm{x}) \cap(\mathrm{L}+\mathrm{T})^{-1}\left(\mathrm{H}_{\mathrm{t}}+\mathrm{T}\right)(\mathrm{x}) \neq \emptyset \text { for some } \mathrm{t} \in[0,1]\right\}
$$

is closed, in Definition 2.13.

Definition 2.18. Let $F: E \rightarrow 2^{Y}$. We say $F \in A(E, Y ; L, T)$ if $(L+T)^{-1}(F+T) \in A(E, E)$.

Definition 2.19. If $F, G \in A(E, Y ; L, T)$ then we say $F \cong G$ in $A(E, Y ; L, T)$ if there exists a map $\wedge: E \times[0,1] \rightarrow$ $2^{Y}$ with $(L+T)^{-1}(\Lambda(., \eta())+T.) \in A(E, E)$ for any continuous function $\eta: E \rightarrow[0,1], \Lambda_{1}=F, \Lambda_{0}=G$ (here $\left.\Lambda_{t}(x)=\Lambda(x, t)\right)$ and

$$
\left\{x \in E:(L+T)^{-1}(\Phi+T)(x) \cap(L+T)^{-1}\left(\Lambda_{t}+T\right)(x) \neq \emptyset \text { for some } t \in[0,1]\right\}
$$

is compact.

We now fix a $\Phi \in B(E, Y ; L, T)$.

Theorem 2.20. Let $\mathrm{E}$ be a completely regular topological vector space, $\mathrm{Y}$ a topological vector space, $\mathrm{U}$ an open subset of $\mathrm{E}, \mathrm{L}: \operatorname{dom}(\mathrm{L}) \subseteq \mathrm{E} \rightarrow \mathrm{Y}$ a linear single valued map, and $\mathrm{T} \in \mathrm{H}_{\mathrm{L}}(\mathrm{E}, \mathrm{Y})$. Suppose there exists a map $\mathrm{H}: \mathrm{E} \times[0,1] \rightarrow 2^{Y}$ with $(\mathrm{L}+\mathrm{T})^{-1}(\mathrm{H}(., \eta())+.\mathrm{T}) \in \mathrm{A}(\mathrm{E}, \mathrm{E})$ for any continuous function $\eta: \mathrm{E} \rightarrow[0,1]$, $(\mathrm{L}+\mathrm{T})^{-1}(\Phi+\mathrm{T})(\mathrm{x}) \cap(\mathrm{L}+\mathrm{T})^{-1}\left(\mathrm{H}_{0}+\mathrm{T}\right)(\mathrm{x})=\emptyset$ for $\mathrm{x} \in \mathrm{E} \backslash \mathrm{U},(\mathrm{L}+\mathrm{T})^{-1}\left(\mathrm{H}_{\mathrm{t}}+\mathrm{T}\right)(\mathrm{x}) \cap(\mathrm{L}+\mathrm{T})^{-1}(\Phi+\mathrm{T})(\mathrm{x})=\emptyset$ for any $\mathrm{x} \in \partial \mathrm{U}$ and $\mathrm{t} \in[0,1]$, and

$$
\left\{x \in E:(L+T)^{-1}(\Phi+T)(x) \cap(L+T)^{-1}\left(H_{t}+T\right)(x) \neq \emptyset \text { for some } t \in[0,1]\right\}
$$

is compact. In addition assume the following conditions holds:

$$
\begin{aligned}
& \left\{\begin{array}{l}
\text { for any } \mathrm{J} \in \mathrm{A}(\mathrm{E}, \mathrm{Y} ; \mathrm{L}, \mathrm{T}) \text { with } \mathrm{J} \cong \mathrm{H}_{0} \text { in } \mathrm{A}(\mathrm{E}, \mathrm{Y} ; \mathrm{L}, \mathrm{T}) \text { there exists } \mathrm{x} \in \mathrm{E} \text { with } \\
(\mathrm{L}+\mathrm{T})^{-1}(\mathrm{~J}+\mathrm{T})(\mathrm{x}) \cap(\mathrm{L}+\mathrm{T})^{-1}(\Phi+\mathrm{T})(\mathrm{x}) \neq \emptyset,
\end{array}\right. \\
& \left\{x \in \mathrm{E} \backslash \mathrm{U}:(\mathrm{L}+\mathrm{T})^{-1}(\Phi+\mathrm{T})(\mathrm{x}) \cap(\mathrm{L}+\mathrm{T})^{-1}\left(\mathrm{H}_{\mathrm{t}}+\mathrm{T}\right)(\mathrm{x}) \neq \emptyset \text { for some } \mathrm{t} \in[0,1]\right\} \text { is closed, }
\end{aligned}
$$

and

$$
\left\{\begin{array}{l}
\text { if } \mu: \mathrm{E} \rightarrow[0,1] \text { is any continuous map with } \mu(\overline{\mathrm{U}})=1 \text {, then } \\
\left\{x \in \mathrm{E}:(\mathrm{L}+\mathrm{T})^{-1}(\Phi+\mathrm{T})(\mathrm{x}) \cap(\mathrm{L}+\mathrm{T})^{-1}\left(\mathrm{H}_{\mathrm{t} \mu(x)}+\mathrm{T}\right)(\mathrm{x}) \neq \emptyset \text { for some } \mathrm{t} \in[0,1]\right\} \text { is closed. }
\end{array}\right.
$$

Then there exists $x \in U$ with $(L+T)^{-1}\left(H_{1}+T\right)(x) \cap(L+T)^{-1}(\Phi+T)(x) \neq \emptyset$; here $H_{t}(x)=H(x, t)$.

Proof. Let

$$
\mathrm{D}=\left\{x \in \mathrm{E} \backslash \mathrm{U}:(\mathrm{L}+\mathrm{T})^{-1}(\Phi+\mathrm{T})(\mathrm{x}) \cap(\mathrm{L}+\mathrm{T})^{-1}\left(\mathrm{H}_{\mathrm{t}}+\mathrm{T}\right)(\mathrm{x}) \neq \emptyset \text { for some } \mathrm{t} \in[0,1]\right\} .
$$

We consider two cases, as $\mathrm{D} \neq \emptyset$ and $\mathrm{D}=\emptyset$. 


\section{Case (i). $\mathrm{D}=\emptyset$.}

Then for every $t \in[0,1]$ we have $(L+T)^{-1}(\Phi+T)(x) \cap(L+T)^{-1}\left(H_{t}+T\right)(x)=\emptyset$ for $x \in E \backslash U$. Also from $H_{1} \cong H_{0}$ in $A(E, Y ; L, T)$ and (2.6) we see there exists $y \in E$ with $(L+T)^{-1}(\Phi+T)(y) \cap(L+T)^{-1}\left(H_{1}+\right.$ $\mathrm{T})(\mathrm{y}) \neq \emptyset$. Since $\mathrm{D}=\emptyset$ we see that $\mathrm{y} \in \mathrm{U}$, and we are finished.

\section{Case (ii). $\mathrm{D} \neq \emptyset$.}

Now (note $H_{1} \cong H_{0}$ in $A(E, Y ; L, T)$ and (2.7)) $D$ is compact, and $D \cap \bar{U} \neq \emptyset$ (since $(L+T)^{-1}\left(H_{t}+T\right)(x) \cap$ $(L+T)^{-1}(\Phi+T)(x)=\emptyset$ for $x \in \partial U$ and $\left.t \in[0,1]\right)$. Then there exists a continuous map $\mu: E \rightarrow[0,1]$ with $\mu(D)=0$ and $\mu(\bar{U})=1$. Define a map $R: E \rightarrow 2^{Y}$ by $R(x)=H(x, \mu(x))$. Note $R \in A(E, Y ; L, T)$. Also note $R \cong H_{0}$ in $A(E, Y ; L, T)$ (to see this let $\Omega: E \times[0,1] \rightarrow 2^{E}$ be given by $\Omega(x, t)=H(x, t \mu(x))$ ). Also $\Omega_{1}=R$ and $\Omega_{0}=\mathrm{H}_{0}$.

Now (2.6) guarantees that there exists $x \in E$ with $\emptyset \neq(L+T)^{-1}(\Phi+T)(x) \cap(L+T)^{-1}(R+T)(x)=$ $(\mathrm{L}+\mathrm{T})^{-1}(\Phi+\mathrm{T})(\mathrm{x}) \cap(\mathrm{L}+\mathrm{T})^{-1}\left(\mathrm{H}_{\mu(x)}+\mathrm{T}\right)(\mathrm{x})$. If $x \in \mathrm{E} \backslash \mathrm{U}$ then since $\mathrm{x} \in \mathrm{D}$ we have $\emptyset \neq(\mathrm{L}+\mathrm{T})^{-1}(\Phi+$ $\mathrm{T})(\mathrm{x}) \cap(\mathrm{L}+\mathrm{T})^{-1}\left(\mathrm{H}_{\mu(x)}+\mathrm{T}\right)(\mathrm{x})=(\mathrm{L}+\mathrm{T})^{-1}(\Phi+\mathrm{T})(\mathrm{x}) \cap(\mathrm{L}+\mathrm{T})^{-1}\left(\mathrm{H}_{0}+\mathrm{T}\right)(\mathrm{x})$, a contradiction. Thus $\mathrm{x} \in \mathrm{U}$ and so $\emptyset \neq(L+T)^{-1}(\Phi+T)(x) \cap(L+T)^{-1}\left(H_{\mu(x)}+T\right)(x)=(L+T)^{-1}(\Phi+T)(x) \cap(L+T)^{-1}\left(H_{1}+T\right)(x)$.

Remark 2.21. In Definition 2.19 and in the statement of Theorem 2.20 we could replace any continuous map $\eta: E \rightarrow[0,1]$ with any continuous map $\eta: E \rightarrow[0,1]$ with $\eta(\bar{U})=1$.

Remark 2.22. There is an analogue of Remark 2.17 (for normal topological vector spaces) in the statement of Theorem 2.20 and in Definition 2.19.

\section{Generalized continuation principles}

Let $E$ be a completely regular topological space and $U$ an open subset of $E$. Again we consider classes A and $\mathbf{B}$ of maps.

In this section we fix a $\Phi \in \mathrm{B}(\overline{\mathrm{U}}, \mathrm{E})$.

For any map $\mathrm{F} \in \overline{\mathrm{A}(\overline{\mathrm{U}}, \mathrm{E})}$ let $\mathrm{F}^{\star}=\mathrm{I} \times \mathrm{F}: \overline{\mathrm{U}} \rightarrow 2^{\overline{\mathrm{U}} \times \mathrm{E}}$, with $\mathrm{I}: \overline{\mathrm{U}} \rightarrow \overline{\mathrm{U}}$ given by $\mathrm{I}(\mathrm{x})=x$, and let

$$
\mathrm{d}:\left\{\left(\mathrm{F}^{\star}\right)^{-1}(\mathrm{~B})\right\} \cup\{\emptyset\} \rightarrow \Omega
$$

be any map with values in the nonempty set $\Omega$; here $B=\{(x, \Phi(x)): x \in \bar{U}\}$.

Definition 3.1. Let $E$ be a completely regular (respectively normal) topological space, and $U$ an open subset of $E$. Let $F, G \in A_{\partial u}(\bar{U}, E)$. We say $F \cong G$ in $A_{\partial u}(\bar{U}, E)$ if there exists a map $H: \bar{U} \times[0,1] \rightarrow 2^{E}$ with $H(., \eta().) \in A(\bar{U}, E)$ for any continuous function $\eta: \bar{U} \rightarrow[0,1]$ with $\eta(\partial U)=0, H_{t}(x) \cap \Phi(x)=\emptyset$ for any $x \in \partial U$ and $t \in[0,1], H_{1}=F, H_{0}=G$ and $\left\{x \in \bar{U}:(x, \Phi(x)) \cap H^{\star}(x, t) \neq \emptyset\right.$ for some $\left.t \in[0,1]\right\}$ is compact (respectively closed); here $H^{\star}(x, t)=(x, H(x, t))$ and $H_{t}(x)=H(x, t)$.

Definition 3.2. Let $F \in A_{\partial u}(\bar{U}, E)$ with $F^{\star}=I \times F$. We say $F^{\star}: \bar{U} \rightarrow 2^{\bar{U} \times E}$ is d- $\Phi$-essential if for every $\operatorname{map} \mathrm{J} \in \mathrm{A}_{\partial \mathrm{u}}(\overline{\mathrm{U}}, \mathrm{E})$ with $\mathrm{J}^{\star}=\mathrm{I} \times \mathrm{J}$ and $\left.\mathrm{J}\right|_{\partial \mathrm{u}}=\left.\mathrm{F}\right|_{\partial \mathrm{u}}$ and $\mathrm{J} \cong \mathrm{F}$ in $A_{\partial \mathrm{u}}(\overline{\mathrm{U}}, \mathrm{E})$ we have that $\mathrm{d}\left(\left(\mathrm{F}^{\star}\right)^{-1}(\mathrm{~B})\right)=$ $\mathrm{d}\left(\left(\mathrm{J}^{\star}\right)^{-1}(\mathrm{~B})\right) \neq \mathrm{d}(\emptyset)$.

Remark 3.3. If $\mathrm{F}^{\star}$ is $\mathrm{d}-\Phi$-essential then

$$
\emptyset \neq\left(\mathrm{F}^{\star}\right)^{-1}(\mathrm{~B})=\left\{x \in \overline{\mathrm{U}}: \mathrm{F}^{\star}(\mathrm{x}) \cap \mathrm{B} \neq \emptyset\right\}=\{x \in \overline{\mathrm{U}}:(\mathrm{x}, \mathrm{F}(\mathrm{x})) \cap(\mathrm{x}, \Phi(\mathrm{x})) \neq \emptyset\},
$$

and this together with $F(x) \cap \Phi(x)=\emptyset$ for $x \in \partial U$ implies that there exists $x \in U$ with $(x, \Phi(x)) \cap F^{\star}(x) \neq \emptyset$ (i.e., $\Phi(x) \cap F(x) \neq \emptyset$ ).

Theorem 3.4. Let $\mathrm{E}$ be a completely regular (respectively normal) topological space, $\mathrm{U}$ an open subset of $\mathrm{E}$, $\mathrm{B}=\{(\mathrm{x}, \Phi(\mathrm{x})): \mathrm{x} \in \overline{\mathrm{U}}\}, \mathrm{d}$ a map defined in (3.1) and let $\mathrm{F} \in \mathrm{A}_{\partial \mathrm{u}}(\overline{\mathrm{U}}, \mathrm{E})$ and $\mathrm{F}^{\star}$ be $\mathrm{d}$ - $\Phi$-essential (here $\left.\mathrm{F}^{\star}=\mathrm{I} \times \mathrm{F}\right)$. Suppose there exists a map $\mathrm{H}: \overline{\mathrm{U}} \times[0,1] \rightarrow 2^{\mathrm{E}}$ with $\mathrm{H}(., \eta().) \in A(\overline{\mathrm{U}}, \mathrm{E})$ for any continuous function $\eta: \overline{\mathrm{U}} \rightarrow[0,1]$ with $\eta(\partial \mathrm{U})=0, \mathrm{H}_{\mathrm{t}}(\mathrm{x}) \cap \Phi(\mathrm{x})=\emptyset$ for any $\mathrm{x} \in \partial \mathrm{U}$ and $\mathrm{t} \in(0,1], \mathrm{H}_{0}=\mathrm{F}$ and 
$\left\{x \in \overline{\mathrm{U}}:(x, \Phi(x)) \cap \mathrm{H}^{\star}(\mathrm{x}, \mathrm{t}) \neq \emptyset\right.$ for some $\left.\mathrm{t} \in[0,1]\right\}$ is compact (respectively closed); here $\mathrm{H}^{\star}(\mathrm{x}, \mathrm{t})=(\mathrm{x}, \mathrm{H}(\mathrm{x}, \mathrm{t}))$ and $\mathrm{H}_{\mathrm{t}}(\mathrm{x})=\mathrm{H}(\mathrm{x}, \mathrm{t})$. In addition assume

$$
\left\{\begin{array}{l}
\text { if } \mu: \overline{\mathrm{U}} \rightarrow[0,1] \text { is any continuous map with } \mu(\partial \mathrm{U})=0 \text {, then } \\
\{x \in \overline{\mathrm{U}}:(\mathrm{x}, \Phi(\mathrm{x})) \cap(\mathrm{x}, \mathrm{H}(\mathrm{x}, \mathrm{t} \mu(\mathrm{x}))) \neq \emptyset \text { for some } \mathrm{t} \in[0,1]\} \text { is closed. }
\end{array}\right.
$$

Let $\mathrm{H}_{1}^{\star}=\mathrm{I} \times \mathrm{H}_{1}$. Then

$$
\mathrm{d}\left(\left(\mathrm{H}_{1}^{\star}\right)^{-1}(\mathrm{~B})\right)=\mathrm{d}\left(\left(\mathrm{F}^{\star}\right)^{-1}(\mathrm{~B})\right) \neq \mathrm{d}(\emptyset) .
$$

Proof. Let

$$
\mathrm{D}=\left\{x \in \overline{\mathrm{U}}:(x, \Phi(x)) \cap \mathrm{H}^{\star}(x, \mathrm{t}) \neq \emptyset \text { for some } \mathrm{t} \in[0,1]\right\},
$$

where $H^{\star}(x, t)=(x, H(x, t))$. Notice $D \neq \emptyset$ since $F^{\star}$ is $d-\Phi$-essential. Also $D$ is compact (respectively closed) if $E$ is a completely regular (respectively normal) topological space and $D \cap \partial U=\emptyset$. Thus there exists a continuous map $\mu: \bar{U} \rightarrow[0,1]$ with $\mu(\partial U)=0$ and $\mu(D)=1$. Define $R_{\mu}: \bar{U} \rightarrow 2^{E}$ by $R_{\mu}(x)=$ $H(x, \mu(x))$ and let $R_{\mu}^{\star}=I \times R_{\mu}$. Note $R_{\mu} \in A_{\partial u}(\bar{U}, E)$ with $R_{\mu} l_{\partial u}=\left.F\right|_{\partial u}$ (note if $x \in \partial U$ then $R_{\mu}(x)=$ $\mathrm{H}_{0}(\mathrm{x})=\mathrm{F}(\mathrm{x})$ and $\left.\mathrm{R}_{\mu}(\mathrm{x}) \cap \Phi(\mathrm{x})=\mathrm{F}(\mathrm{x}) \cap \Phi(\mathrm{x})=\emptyset\right)$.

Next we note since $\mu(D)=1$ that

$$
\left(R_{\mu}^{\star}\right)^{-1}(B)=\left\{x \in \overline{\mathrm{U}}:(x, \Phi(x)) \cap(x, H(x, \mu(x)) \neq \emptyset\}=\left\{x \in \overline{\mathrm{U}}:(x, \Phi(x)) \cap(x, H(x, 1) \neq \emptyset\}=\left(H_{1}^{\star}\right)^{-1}(B),\right.\right.
$$

so

$$
\mathrm{d}\left(\left(\mathrm{R}_{\mu}^{\star}\right)^{-1}(\mathrm{~B})\right)=\mathrm{d}\left(\left(\mathrm{H}_{1}^{\star}\right)^{-1}(\mathrm{~B})\right)
$$

Also note $R_{\mu} \cong F$ in $A_{\partial u}(\bar{U}, E)$ (to see this let $Q: \bar{U} \times[0,1] \rightarrow 2^{E}$ be given by $Q(x, t)=H(x, t \mu(x))$ ). As a result since $F^{\star}$ is $d$ - $\Phi$-essential we have $d\left(\left(R_{\mu}^{\star}\right)^{-1}(B)\right)=d\left(\left(F^{\star}\right)^{-1}(B)\right) \neq d(\emptyset)$. This together with (3.2) yields $d\left(\left(H_{1}^{\star}\right)^{-1}(B)\right)=d\left(\left(F^{\star}\right)^{-1}(B)\right) \neq d(\emptyset)$.

Remark 3.5. Suppose we change Definition 3.2 as follows. Let $F \in A_{\partial u}(\bar{U}, E)$ with $F^{\star}=I \times F$. We say $F^{\star}: \bar{U} \rightarrow 2^{\bar{U} \times E}$ is $d-\Phi$-essential if for every map $J \in A_{\partial u}(\bar{U}, E)$ with $J^{\star}=I \times J$ and $\left.J\right|_{\partial u}=\left.F\right|_{\partial u}$ we have that $d\left(\left(F^{\star}\right)^{-1}(B)\right)=d\left(\left(J^{\star}\right)^{-1}(B)\right) \neq d(\emptyset)$. The argument above yields the following result. Let $E$ be a completely regular (respectively normal) topological space, $U$ an open subset of $E$, $\mathrm{B}=\{(\mathrm{x}, \Phi(\mathrm{x})): \mathrm{x} \in \overline{\mathrm{U}}\}, \mathrm{d}$ a map defined in (3.1) and let $\mathrm{F} \in A_{\partial \mathrm{u}}(\overline{\mathrm{U}}, \mathrm{E})$ and $\mathrm{F}^{\star}$ be $\mathrm{d}$ - $\Phi$-essential (here $\left.\mathrm{F}^{\star}=\mathrm{I} \times \mathrm{F}\right)$. Suppose there exists a map $\mathrm{H}: \overline{\mathrm{U}} \times[0,1] \rightarrow 2^{\mathrm{E}}$ with $\mathrm{H}(., \eta().) \in A(\overline{\mathrm{U}}, \mathrm{E})$ for any continuous function $\eta: \overline{\mathrm{U}} \rightarrow[0,1]$ with $\eta(\partial \mathrm{U})=0, \mathrm{H}_{\mathrm{t}}(\mathrm{x}) \cap \Phi(x)=\emptyset$ for any $x \in \partial \mathrm{U}$ and $\mathrm{t} \in(0,1]$, $\mathrm{H}_{0}=\mathrm{F}$ and $\left\{x \in \overline{\mathrm{U}}:(x, \Phi(x)) \cap \mathrm{H}^{\star}(x, t) \neq \emptyset\right.$ for some $\left.\mathrm{t} \in[0,1]\right\}$ is compact (respectively closed); here $H^{\star}(x, t)=(x, H(x, t))$ and $H_{t}(x)=H(x, t)$. Then $d\left(\left(H_{1}^{\star}\right)^{-1}(B)\right)=d\left(\left(F^{\star}\right)^{-1}(B)\right) \neq d(\emptyset)$.

Remark 3.6. Suppose the following conditions holds (which is common in the literature on topological degree):

$$
\left\{\begin{array}{l}
\text { if } F, G \in A_{\partial u}(\bar{U}, E) \text { with }\left.F\right|_{\partial u}=\left.G\right|_{\partial u} \text { and } F \cong G \\
\text { in } A_{\partial u}(\bar{U}, E) \text {, then } d\left(\left(F^{\star}\right)^{-1}(B)\right)=d\left(\left(G^{\star}\right)^{-1}(B)\right) .
\end{array}\right.
$$

Then Definition 3.2 reduces to the following. Let $F \in A_{\partial U}(\bar{U}, E)$ with $F^{\star}=I \times F$. We say $F^{\star}: \bar{U} \rightarrow 2^{\bar{U} \times E}$ is $\mathrm{d}$ - $\Phi$-essential if $\mathrm{d}\left(\left(\mathrm{F}^{\star}\right)^{-1}(\mathrm{~B})\right) \neq \mathrm{d}(\emptyset)$.

Next in this paper we use the notion of extendability to establish new continuation theorems.

Definition 3.7. We say $F \in A(E, E)$ if $F: E \rightarrow 2^{E}$ and $F \in A(E, E)$. 
We now fix a $\Phi \in B(E, E)$.

For any map $\mathrm{F} \in \mathrm{A}(\mathrm{E}, \mathrm{E})$ let $\mathrm{F}^{\star}=\mathrm{I} \times \mathrm{F}: \mathrm{E} \rightarrow 2^{\mathrm{E} \times \mathrm{E}}$, with $\mathrm{I}: \mathrm{E} \rightarrow \mathrm{E}$ given by $\mathrm{I}(\mathrm{x})=x$, and let

$$
\mathrm{d}:\left\{\left(\mathrm{F}^{\star}\right)^{-1}(\mathrm{~B})\right\} \cup\{\emptyset\} \rightarrow \Omega
$$

be any map with values in the nonempty set $\Omega$; here $B=\{(x, \Phi(x)): x \in E\}$. In our applications we will be interested in maps $\mathrm{F}: \overline{\mathrm{U}} \rightarrow 2^{\mathrm{E}}$ so $\mathrm{F}^{\star}=\mathrm{I} \times \mathrm{F}: \overline{\mathrm{U}} \rightarrow 2^{\overline{\mathrm{U}} \times \mathrm{E}}$ and in this case we consider

$$
\mathrm{d}:\left\{\left(\mathrm{F}^{\star}\right)^{-1}(\mathrm{~B} \mathrm{U})\right\} \cup\{\emptyset\} \rightarrow \Omega,
$$

where $B_{U}=\{(x, \Phi(x)): x \in U\}$.

Definition 3.8. If $F, G \in A(E, E)$, then we say $F \cong G$ in $A(E, E)$ if there exists a map $\wedge: E \times[0,1] \rightarrow 2^{E}$ with $\Lambda(., \eta().) \in A(E, E)$ for any continuous function $\eta: E \rightarrow[0,1], \Lambda_{1}=F, \Lambda_{0}=G$ (here $\Lambda_{t}(x)=\Lambda(x, t)$ ) and $\left\{x \in E:(x, \Phi(x)) \cap \Lambda^{\star}(x, t) \neq \emptyset\right.$ for some $\left.t \in[0,1]\right\}$ is compact (respectively closed); here $\Lambda^{\star}(x, t)=$ $(x, \wedge(x, t))$.

Theorem 3.9. Let $\mathrm{E}$ be a completely regular (respectively normal) topological space, $\mathrm{U}$ an open subset of $\mathrm{E}$ and $\mathrm{d} a$ map defined in (3.4). Suppose there exists a map $\mathrm{H}: \mathrm{E} \times[0,1] \rightarrow 2^{\mathrm{E}}$ with $\mathrm{H}(., \eta().) \in \mathrm{A}(\mathrm{E}, \mathrm{E})$ for any continuous function $\eta: \mathrm{E} \rightarrow[0,1]$ and with $\Phi(\mathrm{x}) \cap \mathrm{H}(\mathrm{x}, 0)=\emptyset$ for $\mathrm{x} \in \mathrm{E} \backslash \mathrm{U}$, and $\Phi(\mathrm{x}) \cap \mathrm{H}_{\mathrm{t}}(\mathrm{x})=\emptyset$ for any $\mathrm{x} \in \partial \mathrm{U}$ and $\mathrm{t} \in[0,1]$, and

$$
\{x \in \mathrm{E}:(x, \Phi(x)) \cap(x, \mathrm{H}(x, \mathrm{t})) \neq \emptyset \text { for some } \mathrm{t} \in[0,1]\}
$$

is compact (respectively closed). In addition assume the following hold:

$$
\begin{aligned}
& \left\{\begin{array}{l}
\text { for any } \mathrm{J} \in \mathrm{A}(\mathrm{E}, \mathrm{E}) \text { with } \mathrm{J}^{\star}=\mathrm{I} \times \mathrm{J} \text { and } \mathrm{J} \cong \mathrm{H}_{0} \text { in } \mathrm{A}(\mathrm{E}, \mathrm{E}) \text { we have that } \\
\mathrm{d}\left(\left(\mathrm{J}^{\star}\right)^{-1}(\mathrm{~B})\right)=\mathrm{d}\left(\left(\mathrm{H}_{0}^{\star}\right)^{-1}(\mathrm{~B})\right) \neq \mathrm{d}(\emptyset),
\end{array}\right. \\
& \left\{\mathrm{x} \in \mathrm{E} \backslash \mathrm{U}:(\mathrm{x}, \Phi(\mathrm{x})) \cap \mathrm{H}^{\star}(\mathrm{x}, \mathrm{t}) \neq \emptyset \text { for some } \mathrm{t} \in[0,1]\right\} \text { is closed, }
\end{aligned}
$$

and

$$
\left\{\begin{array}{l}
\text { if } \mu: \mathrm{E} \rightarrow[0,1] \text { is any continuous map with } \mu(\overline{\mathrm{U}})=1 \text {, then } \\
\{x \in \mathrm{E}: \emptyset \neq(x, \Phi(\mathrm{x})) \cap(x, \mathrm{H}(\mathrm{x}, \mathrm{t} \mu(\mathrm{x}))) \text { for some } \mathrm{t} \in[0,1]\} \text { is closed; }
\end{array}\right.
$$

here $\mathrm{H}_{0}^{\star}=\mathrm{I} \times \mathrm{H}_{0}$ and $\mathrm{H}^{\star}(\mathrm{x}, \mathrm{t})=(\mathrm{x}, \mathrm{H}(\mathrm{x}, \mathrm{t}))$. Let $\mathrm{H}_{1}^{\star}=\mathrm{I} \times \mathrm{H}_{1}$. Then we have

$$
\mathrm{d}\left(\left(\mathrm{H}_{1}^{\star}\right)^{-1}\left(\mathrm{~B}_{\mathrm{u}}\right)\right)=\mathrm{d}\left(\left(\mathrm{H}_{0}^{\star}\right)^{-1}\left(\mathrm{~B}_{\mathrm{u}}\right)\right) \neq \mathrm{d}(\emptyset) .
$$

Proof. Let

$$
\mathrm{D}=\left\{x \in \mathrm{E} \backslash \mathrm{U}:(x, \Phi(x)) \cap \mathrm{H}^{\star}(\mathrm{x}, \mathrm{t}) \neq \emptyset \text { for some } \mathrm{t} \in[0,1]\right\},
$$

where $H^{\star}(x, t)=(x, H(x, t))$.

We consider two cases, as $\mathrm{D} \neq \emptyset$ and $\mathrm{D}=\emptyset$.

Case (i). $\mathrm{D}=\emptyset$.

Then for every $t \in[0,1]$ we have $\Phi(x) \cap H_{t}(x)=\emptyset$ for $x \in E \backslash U$. Also from $H_{1} \cong H_{0}$ in $A(E, E)$ and (3.5) we have

$$
\mathrm{d}\left(\left(\mathrm{H}_{1}^{\star}\right)^{-1}(\mathrm{~B})\right)=\mathrm{d}\left(\left(\mathrm{H}_{0}^{\star}\right)^{-1}(\mathrm{~B})\right) \neq \mathrm{d}(\emptyset) .
$$

Note $\left(H_{1}^{\star}\right)^{-1}(B)=\left\{x \in E:(x, \Phi(x)) \cap\left(x, H_{1}(x)\right) \neq \emptyset\right\}$. Consider $y \in E$ and $(y, \Phi(y)) \cap H_{1}^{\star}(y) \neq \emptyset$. Then $y \in E$ and $\Phi(y) \cap H_{1}(y) \neq \emptyset$. Now since $D=\emptyset$ we have $y \in U$ and $\Phi(y) \cap H_{1}(y) \neq \emptyset$ i.e., $y \in U$ and $(y, \Phi(y)) \cap H_{1}^{\star}(y) \neq \emptyset$. Consequently $\left(H_{1}^{\star}\right)^{-1}(B) \subseteq\left(H_{1}^{\star}\right)^{-1}(B u)$ and on the other hand it is immediate that $\left(\mathrm{H}_{1}^{\star}\right)^{-1}\left(\mathrm{Bu}_{\mathrm{U}}\right) \subseteq\left(\mathrm{H}_{1}^{\star}\right)^{-1}(\mathrm{~B})$. Thus $\left(\mathrm{H}_{1}^{\star}\right)^{-1}(\mathrm{~B})=\left(\mathrm{H}_{1}^{\star}\right)^{-1}\left(\mathrm{Bu}_{\mathrm{U}}\right)$. It is also immediate that $\left(\mathrm{H}_{0}^{\star}\right)^{-1}(\mathrm{~B})=\left(\mathrm{H}_{0}^{\star}\right)^{-1}(\mathrm{Bu})$.

Thus (3.7) implies $\mathrm{d}\left(\left(\mathrm{H}_{1}^{\star}\right)^{-1}\left(\mathrm{Bu}_{\mathrm{u}}\right)=\mathrm{d}\left(\left(\mathrm{H}_{0}^{\star}\right)^{-1}\left(\mathrm{~B}_{\mathrm{u}}\right)\right)\right) \neq \mathrm{d}(\emptyset)$, and we are finished. 
Case (ii). $\mathrm{D} \neq \emptyset$.

Note $\mathrm{D}$ is compact (respectively closed) and also note $\mathrm{D} \cap \overline{\mathrm{U}} \neq \emptyset$ (since $\Phi(x) \cap \mathrm{H}_{\mathrm{t}}(\mathrm{x})=\emptyset$ for $x \in \partial \mathrm{U}$ and $t \in[0,1])$. Then there exists a continuous map $\mu: E \rightarrow[0,1]$ with $\mu(D)=0$ and $\mu(\bar{U})=1$. Define a map $R: E \rightarrow 2^{E}$ by $R(x)=H(x, \mu(x))$. Note $R \in A(E, E)$. In fact $R \cong H_{0}$ in $A(E, E)$. To see this let $\Lambda: E \times[0,1] \rightarrow 2^{E}$ be given by $\Lambda(x, t)=H(x, t \mu(x))$. Note $\Lambda(., \eta().) \in A(E, E)$ for any continuous function $\eta: E \rightarrow[0,1]$, and (note (3.6) and $H_{1} \cong H_{0}$ in $A(E, E)$ ),

$$
\{x \in E:(x, \Phi(x)) \cap(x, H(x, t \mu(x))) \neq \emptyset \text { for some } t \in[0,1]\}
$$

is compact (respectively closed). Also $\Lambda_{1}=\mathrm{R}$ and $\Lambda_{0}=\mathrm{H}_{0}$.

Let $R^{\star}=I \times R$. Now (3.5) guarantees that

$$
\mathrm{d}\left(\left(\mathrm{R}^{\star}\right)^{-1}(\mathrm{~B})\right)=\mathrm{d}\left(\left(\mathrm{H}_{0}^{\star}\right)^{-1}(\mathrm{~B})\right) \neq \mathrm{d}(\emptyset) .
$$

Note $\left(R^{\star}\right)^{-1}(B)=\{x \in E:(x, \Phi(x)) \cap(x, R(x)) \neq \emptyset\}$. Consider $x \in E$ and $(x, \Phi(x)) \cap R^{\star}(x) \neq \emptyset$. Then $x \in E$ and $\emptyset \neq \Phi(x) \cap R(x)=\Phi(x) \cap H_{\mu(x)}(x)$. If $x \in E \backslash U$ then since $x \in D$ we have $\emptyset \neq \Phi(x) \cap H_{\mu(x)}(x)=\Phi(x) \cap$ $\mathrm{H}(x, 0)$, which is a contradiction. Thus $x \in U$ and $\emptyset \neq \Phi(x) \cap R(x)$. Consequently $\left(R^{\star}\right)^{-1}(B) \subseteq\left(R^{\star}\right)^{-1}(B U)$ and on the other hand it is immediate that $\left(R^{\star}\right)^{-1}\left(B_{U}\right) \subseteq\left(R^{\star}\right)^{-1}(B)$. Thus $\left(R^{\star}\right)^{-1}(B)=\left(R^{\star}\right)^{-1}(B u)$. Also $\left(\mathrm{H}_{0}^{\star}\right)^{-1}(\mathrm{~B})=\left(\mathrm{H}_{0}^{\star}\right)^{-1}\left(\mathrm{~B}_{\mathrm{U}}\right)$. Thus (3.8) implies

$$
\mathrm{d}\left(\left(\mathrm{R}^{\star}\right)^{-1}\left(\mathrm{~B}_{\mathrm{U}}\right)\right)=\mathrm{d}\left(\left(\mathrm{H}_{0}^{\star}\right)^{-1}\left(\mathrm{~B}_{\mathrm{U}}\right)\right) \neq \mathrm{d}(\emptyset) .
$$

Finally notice $($ note $\mu(\overline{\mathrm{U}})=1)$ that

$$
\begin{aligned}
\left(\mathrm{R}^{\star}\right)^{-1}(\mathrm{Bu}) & =\{x \in \mathrm{U}:(x, \Phi(x)) \cap(x, H(x, \mu(x))) \neq \emptyset\} \\
& =\{x \in \mathrm{U}:(x, \Phi(x)) \cap(x, H(x, 1)) \neq \emptyset\}=\left(\mathrm{H}_{1}^{\star}\right)^{-1}\left(\mathrm{Bu}_{\mathrm{u}}\right),
\end{aligned}
$$

so from (3.9) we have $\mathrm{d}\left(\left(\mathrm{H}_{1}^{\star}\right)^{-1}\left(\mathrm{~B}_{\mathrm{u}}\right)\right)=\mathrm{d}\left(\left(\mathrm{H}_{0}^{\star}\right)^{-1}\left(\mathrm{~B}_{\mathrm{u}}\right)\right) \neq \mathrm{d}(\emptyset)$.

Remark 3.10. In Definition 3.8 and in the statement of Theorem 3.9 we could replace, any continuous map $\eta: E \rightarrow[0,1]$, with, any continuous map $\eta: E \rightarrow[0,1]$ with $\eta(\bar{U})=1$.

Let $E$ be a topological vector space, $Y$ a topological vector space, $U$ an open subset of $E, L: \operatorname{dom}(L) \subseteq$ $E \rightarrow Y$ a linear single valued map, and $T \in H_{L}(E, Y)$.

We now fix a $\Phi \in B(\bar{U}, Y ; L, T)$.

For any map $F \in A(\bar{U}, Y ; L, T)$ let $F^{\star}=I \times(L+T)^{-1}(F+T): \bar{U} \rightarrow 2^{\bar{U} \times E}$, with $I: \bar{U} \rightarrow \bar{U}$ given by $\mathrm{I}(\mathrm{x})=\mathrm{x}$, and let

$$
\mathrm{d}:\left\{\left(\mathrm{F}^{\star}\right)^{-1}(\mathrm{~B})\right\} \cup\{\emptyset\} \rightarrow \Omega
$$

be any map with values in the nonempty set $\Omega$; here $B=\left\{\left(x,(L+T)^{-1}(\Phi+T)(x)\right): x \in \bar{U}\right\}$.

Definition 3.11. Let $F, G \in A_{\partial u}(\bar{U}, Y ; L, T)$. We say $F \cong G$ in $A_{\partial u}(\bar{U}, Y ; L, T)$ if there exists a map $H$ : $\overline{\mathrm{U}} \times[0,1] \rightarrow 2^{\mathrm{Y}}$ with $(\mathrm{L}+\mathrm{T})^{-1}(\mathrm{H}(., \eta())+.\mathrm{T}().) \in \mathrm{A}(\overline{\mathrm{U}}, \mathrm{E})$ for any continuous function $\eta: \overline{\mathrm{U}} \rightarrow[0,1]$ with $\eta(\partial \mathrm{U})=0,(\mathrm{~L}+\mathrm{T})^{-1}\left(\mathrm{H}_{\mathrm{t}}+\mathrm{T}\right)(\mathrm{x}) \cap(\mathrm{L}+\mathrm{T})^{-1}(\Phi+\mathrm{T})(\mathrm{x})=\emptyset$ for any $\mathrm{x} \in \partial \mathrm{U}$ and $\mathrm{t} \in[0,1], \mathrm{H}_{1}=\mathrm{F}, \mathrm{H}_{0}=\mathrm{G}$ and

$$
\left\{x \in \overline{\mathrm{U}}:\left(x,(\mathrm{~L}+\mathrm{T})^{-1}(\Phi+\mathrm{T})(x)\right) \cap \mathrm{H}^{\star}(x, \mathrm{t}) \neq \emptyset \text { for some } \mathrm{t} \in[0,1]\right\}
$$

is compact; here $H_{t}(x)=H(x, t)$ and $H^{\star}(x, \lambda)=\left(x,(L+T)^{-1}(H+T)(x, \lambda)\right)$.

Definition 3.12. Let $F \in A_{\partial u}(\bar{U}, Y ; L, T)$ with $F^{\star}=I \times(L+T)^{-1}(F+T)$. We say $F^{\star}: \bar{U} \rightarrow 2^{\bar{U} \times E}$ is d-L- $\Phi$ essential if for every map $\mathrm{J} \in \mathrm{A}_{\partial \mathrm{u}}(\overline{\mathrm{U}}, \mathrm{Y} ; \mathrm{L}, \mathrm{T})$ with $\mathrm{J}^{\star}=\mathrm{I} \times(\mathrm{L}+\mathrm{T})^{-1}(\mathrm{~J}+\mathrm{T})$ and $\left.\mathrm{J}\right|_{\partial \mathrm{u}}=\left.\mathrm{F}\right|_{\partial \mathrm{u}}$ and $\mathrm{J} \cong \mathrm{F}$ in $A_{\partial u}(\bar{U}, Y ; L, T)$ we have that $d\left(\left(F^{\star}\right)^{-1}(B)\right)=d\left(\left(J^{\star}\right)^{-1}(B)\right) \neq d(\emptyset)$. 
Theorem 3.13. Let $\mathrm{E}$ be a Hausdorff topological vector space, $\mathrm{Y}$ a topological vector space, $\mathrm{U}$ an open subset of $\mathrm{E}$, $\mathrm{B}=\left\{\left(\mathrm{x},(\mathrm{L}+\mathrm{T})^{-1}(\Phi+\mathrm{T})(\mathrm{x})\right): \mathrm{x} \in \overline{\mathrm{U}}\right\}, \mathrm{L}: \operatorname{dom}(\mathrm{L}) \subseteq \mathrm{E} \rightarrow \mathrm{Y}$ a linear single valued map, $\mathrm{T} \in \mathrm{H}_{\mathrm{L}}(\mathrm{E}, \mathrm{Y}), \mathrm{d} a$ map defined in (3.10), and let $\mathrm{F} \in A_{\partial \mathrm{u}}(\overline{\mathrm{U}}, \mathrm{Y} ; \mathrm{L}, \mathrm{T})$ and $\mathrm{F}^{\star}$ be $\mathrm{d}$-L- $\Phi$-essential (here $\mathrm{F}^{\star}=\mathrm{I} \times(\mathrm{L}+\mathrm{T})^{-1}(\mathrm{~F}+\mathrm{T})$ ). Suppose here exists a map $\mathrm{H}: \overline{\mathrm{U}} \times[0,1] \rightarrow 2^{\mathrm{Y}}$ with $(\mathrm{L}+\mathrm{T})^{-1}(\mathrm{H}(., \eta())+.\mathrm{T}().) \in A(\overline{\mathrm{U}}, \mathrm{E})$ for any continuous function $\eta: \overline{\mathrm{U}} \rightarrow[0,1]$ with $\eta(\partial \mathrm{U})=0,(\mathrm{~L}+\mathrm{T})^{-1}\left(\mathrm{H}_{\mathrm{t}}+\mathrm{T}\right)(\mathrm{x}) \cap(\mathrm{L}+\mathrm{T})^{-1}(\Phi+\mathrm{T})(\mathrm{x})=\emptyset$ for any $\mathrm{x} \in \partial \mathrm{U}$ and $\mathrm{t} \in(0,1], \mathrm{H}_{0}=\mathrm{F}$, and

$$
\left\{x \in \overline{\mathrm{U}}:\left(x,(\mathrm{~L}+\mathrm{T})^{-1}(\Phi+\mathrm{T})(\mathrm{x})\right) \cap \mathrm{H}^{\star}(\mathrm{x}, \mathrm{t}) \neq \emptyset \text { for some } \mathrm{t} \in[0,1]\right\}
$$

is compact; here $\mathrm{H}_{\mathrm{t}}(\mathrm{x})=\mathrm{H}(\mathrm{x}, \mathrm{t})$ and $\mathrm{H}^{\star}(\mathrm{x}, \lambda)=\left(\mathrm{x},(\mathrm{L}+\mathrm{T})^{-1}(\mathrm{H}+\mathrm{T})(\mathrm{x}, \lambda)\right)$. In addition assume

$\{$ if $\mu: \overline{\mathrm{U}} \rightarrow[0,1]$ is any continuous map with $\mu(\partial \mathrm{U})=0$, then

$\left\{\left\{x \in \overline{\mathrm{U}}:\left(x,(\mathrm{~L}+\mathrm{T})^{-1}(\Phi+\mathrm{T})(\mathrm{x})\right) \cap\left(\mathrm{x},(\mathrm{L}+\mathrm{T})^{-1}\left(\mathrm{H}_{\mathrm{t} \mu(\mathrm{x})}+\mathrm{T}\right)(\mathrm{x})\right) \neq \emptyset\right.\right.$ for some $\left.\mathrm{t} \in[0,1]\right\}$ is closed.

Let $\mathrm{H}_{1}^{\star}=\mathrm{I} \times(\mathrm{L}+\mathrm{T})^{-1}\left(\mathrm{H}_{1}+\mathrm{T}\right)$. Then

$$
\mathrm{d}\left(\left(\mathrm{H}_{1}^{\star}\right)^{-1}(\mathrm{~B})\right)=\mathrm{d}\left(\left(\mathrm{F}^{\star}\right)^{-1}(\mathrm{~B})\right) \neq \mathrm{d}(\emptyset) .
$$

Proof. Let

$$
\mathrm{D}=\left\{x \in \overline{\mathrm{U}}:\left(x,(\mathrm{~L}+\mathrm{T})^{-1}(\Phi+\mathrm{T})(\mathrm{x})\right) \cap \mathrm{H}^{\star}(\mathrm{x}, \mathrm{t}) \neq \emptyset \text { for some } \mathrm{t} \in[0,1]\right\},
$$

where $H^{\star}(x, \lambda)=\left(x,(L+T)^{-1}(H+T)(x, \lambda)\right)$. Notice $D \neq \emptyset, D$ is compact, and $D \cap \partial U=\emptyset$. Thus there exists a continuous map $\mu: \overline{\mathrm{U}} \rightarrow[0,1]$ with $\mu(\partial \mathrm{U})=0$ and $\mu(\mathrm{D})=1$. Define $\mathrm{R}_{\mu}: \overline{\mathrm{U}} \rightarrow 2^{\mathrm{Y}}$ by $R_{\mu}(x)=H(x, \mu(x))=H_{\mu(x)}(x)$ and let $R_{\mu}^{\star}=I \times(L+T)^{-1}\left(R_{\mu}+T\right)$. Note $R_{\mu} \in A_{\partial u}(\bar{U}, Y ; L, T)$ with $\left.\mathrm{R}_{\mu}\right|_{\partial \mathrm{u}}=\left.\mathrm{F}\right|_{\partial u}$ (note if $\mathrm{x} \in \partial \mathrm{U}$ then $\mathrm{R}_{\mu}(\mathrm{x})=\mathrm{H}_{0}(\mathrm{x})=\mathrm{F}(\mathrm{x})$ and $\mathrm{R}_{\mu}(\mathrm{x}) \cap \Phi(\mathrm{x})=\mathrm{F}(\mathrm{x}) \cap \Phi(\mathrm{x})=\emptyset$ ).

Next we note, since $\mu(D)=1$, that

$$
\begin{aligned}
\left(R_{\mu}^{\star}\right)^{-1}(B) & =\left\{x \in \overline{\mathrm{U}}:\left(x,(L+T)^{-1}(\Phi+T)(x)\right) \cap\left(x,(L+T)^{-1}\left(H_{\mu(x)}+T\right)(x)\right) \neq \emptyset\right\} \\
& \left.=\left\{x \in \bar{U}:\left(x,(L+T)^{-1}(\Phi+T)(x)\right) \cap x,(L+T)^{-1}\left(H_{1}+T\right)(x)\right) \neq \emptyset\right\}=\left(H_{1}^{\star}\right)^{-1}(B)
\end{aligned}
$$

and so

$$
d\left(\left(R_{\mu}^{\star}\right)^{-1}(B)\right)=d\left(\left(H_{1}^{\star}\right)^{-1}(B)\right)
$$

Also note $R_{\mu} \cong F$ in $A_{\partial u}(\bar{U}, Y ; L, T)$ (to see this let $Q: \bar{U} \times[0,1] \rightarrow 2^{Y}$ be given by $Q(x, t)=H(x, t \mu(x))$ ). As a result since $F^{\star}$ is $d$-L- $\Phi$-essential we have $d\left(\left(R_{\mu}^{\star}\right)^{-1}(B)\right)=d\left(\left(F^{\star}\right)^{-1}(B)\right) \neq d(\emptyset)$. This together with (3.11) yields $d\left(\left(H_{1}^{\star}\right)^{-1}(B)\right)=d\left(\left(F^{\star}\right)^{-1}(B)\right) \neq d(\emptyset)$.

Remark 3.14. Suppose we change Definition 3.12 as follows. Let $F \in A_{\partial u}(\bar{U}, Y ; L, T)$ with $F^{\star}=I \times(L+$ $T)^{-1}(F+T)$. We say $F^{\star}: \bar{U} \rightarrow 2^{\bar{U} \times E}$ is $d-L-\Phi$-essential if for every map $J \in A_{\partial u}(\bar{U}, Y ; L, T)$ with $J^{\star}=$ $\mathrm{I} \times(\mathrm{L}+\mathrm{T})^{-1}(\mathrm{~J}+\mathrm{T})$ and $\left.\mathrm{J}\right|_{\partial \mathrm{u}}=\left.\mathrm{F}\right|_{\text {au }}$ we have that $\mathrm{d}\left(\left(\mathrm{F}^{\star}\right)^{-1}(\mathrm{~B})\right)=\mathrm{d}\left(\left(\mathrm{J}^{\star}\right)^{-1}(\mathrm{~B})\right) \neq \mathrm{d}(\emptyset)$. The argument above yields the following result. Let $E$ be a Hausdorff topological vector space, $Y$ a topological vector space, $\mathrm{U}$ an open subset of $\mathrm{E}, \mathrm{B}=\left\{\left(x,(\mathrm{~L}+\mathrm{T})^{-1}(\Phi+T)(x)\right): x \in \overline{\mathrm{U}}\right\}, \mathrm{L}: \operatorname{dom}(\mathrm{L}) \subseteq \mathrm{E} \rightarrow \mathrm{Y}$ a linear single valued map, $T \in H_{L}(E, Y)$, d a map defined in (3.10) and let $F \in A_{\partial u}(\bar{U}, Y ; L, T)$ and $F^{\star}$ be dL- $\Phi$-essential (here $F^{\star}=I \times(L+T)^{-1}(F+T)$ ). Suppose here exists a map $H: \bar{U} \times[0,1] \rightarrow 2^{\gamma}$ with $(L+T)^{-1}(H(., \eta())+.T().) \in A(\bar{U}, E)$ for any continuous function $\eta: \bar{U} \rightarrow[0,1]$ with $\eta(\partial U)=0,(L+$ $T)^{-1}\left(H_{t}+T\right)(x) \cap(L+T)^{-1}(\Phi+T)(x)=\emptyset$ for any $x \in \partial U$ and $t \in[0,1], H_{1}=F, H_{0}=G$ and

$$
\left\{x \in \overline{\mathrm{U}}:\left(x,(\mathrm{~L}+\mathrm{T})^{-1}(\Phi+\mathrm{T})(\mathrm{x})\right) \cap \mathrm{H}^{\star}(x, \mathrm{t}) \neq \emptyset \text { for some } \mathrm{t} \in[0,1]\right\}
$$

is compact; here $H_{t}(x)=H(x, t)$ and $H^{\star}(x, \lambda)=\left(x,(L+T)^{-1}(H+T)(x, \lambda)\right)$. Let $H_{1}^{\star}=I \times(L+T)^{-1}\left(H_{1}+T\right)$. Then $d\left(\left(H_{1}^{\star}\right)^{-1}(B)\right)=d\left(\left(F^{\star}\right)^{-1}(B)\right) \neq d(\emptyset)$. 
Remark 3.15. Suppose the following condition holds:

$$
\left\{\begin{array}{l}
\text { if } F, G \in A_{\partial u}(\bar{U}, Y ; L, T) \text { with }\left.F\right|_{\partial u}=\left.G\right|_{\partial u} \text { and } F \cong G \\
\text { in } A_{\partial u}(\bar{U}, Y ; L, T) \text { then } d\left(\left(F^{\star}\right)^{-1}(B)\right)=d\left(\left(G^{\star}\right)^{-1}(B)\right) .
\end{array}\right.
$$

Then Definition 3.12 reduces to the following. Let $F \in A_{\partial u}(\bar{U}, Y ; L, T)$ with $F^{\star}=I \times(L+T)^{-1}(F+T)$. We say $\mathrm{F}^{\star}: \overline{\mathrm{U}} \rightarrow 2^{\overline{\mathrm{U}} \times \mathrm{E}}$ is $\mathrm{d}$-L- $\Phi$-essential if $\mathrm{d}\left(\left(\mathrm{F}^{\star}\right)^{-1}(\mathrm{~B})\right) \neq \mathrm{d}(\emptyset)$.

Remark 3.16. If $\mathrm{E}$ is a normal topological vector space then the assumption that $\mathrm{D}$ (in the proof of Theorem 2.15) is compact, can be replaced by D is closed, in the statement (and proof) of Theorem 3.13 and also the assumption that

$$
\left\{x \in \overline{\mathrm{U}}:\left(x,(\mathrm{~L}+\mathrm{T})^{-1}(\Phi+\mathrm{T})(\mathrm{x})\right) \cap \mathrm{H}^{\star}(x, \mathrm{t}) \neq \emptyset \text { for some } \mathrm{t} \in[0,1]\right\}
$$

is compact, can be replaced by

$$
\left\{x \in \overline{\mathrm{U}}:\left(x,(\mathrm{~L}+\mathrm{T})^{-1}(\Phi+\mathrm{T})(\mathrm{x})\right) \cap \mathrm{H}^{\star}(\mathrm{x}, \mathrm{t}) \neq \emptyset \text { for some } \mathrm{t} \in[0,1]\right\}
$$

is closed, in Definition 3.11; here $H^{\star}(x, \lambda)=\left(x,(L+T)^{-1}(H+T)(x, \lambda)\right)$.

We now fix a $\Phi \in B(E, Y ; L, T)$.

Definition 3.17. Let $F: E \rightarrow 2^{Y}$. We say $F \in A(E, Y ; L, T)$ if $(L+T)^{-1}(F+T) \in A(E, E)$.

For any map $\mathrm{F} \in \mathrm{A}(\mathrm{E}, \mathrm{Y} ; \mathrm{L}, \mathrm{T})$ let $\mathrm{F}^{\star}=\mathrm{I} \times(\mathrm{L}+\mathrm{T})^{-1}(\mathrm{~F}+\mathrm{T}): \mathrm{E} \rightarrow 2^{\mathrm{E} \times \mathrm{E}}$, with $\mathrm{I}: \mathrm{E} \rightarrow \mathrm{E}$ given by $\mathrm{I}(\mathrm{x})=x$, and let

$$
\mathrm{d}:\left\{\left(\mathrm{F}^{\star}\right)^{-1}(\mathrm{~B})\right\} \cup\{\emptyset\} \rightarrow \Omega
$$

be any map with values in the nonempty set $\Omega$; here $B=\left\{\left(x,(L+T)^{-1}(\Phi+T)(x)\right): x \in E\right\}$. In our applications we will be interested in maps $\mathrm{F}: \overline{\mathrm{U}} \rightarrow 2^{\mathrm{Y}}$ so $\mathrm{F}^{\star}=\mathrm{I} \times(\mathrm{L}+\mathrm{T})^{-1}[\mathrm{~F}+\mathrm{T}]: \overline{\mathrm{U}} \rightarrow 2^{\overline{\mathrm{U}} \times \mathrm{E}}$ and in this case we consider

$$
\mathrm{d}:\left\{\left(\mathrm{F}^{\star}\right)^{-1}(\mathrm{Bu})\right\} \cup\{\emptyset\} \rightarrow \Omega,
$$

where $\mathrm{B}_{\mathrm{u}}=\left\{\left(\mathrm{x},(\mathrm{L}+\mathrm{T})^{-1}(\Phi+\mathrm{T})(\mathrm{x})\right): \mathrm{x} \in \mathrm{U}\right\}$.

Definition 3.18. If $F, G \in A(E, Y ; L, T)$ then we say $F \cong G$ in $A(E, Y ; L, T)$ if there exists a map $\wedge: E \times[0,1] \rightarrow$ $2^{Y}$ with $(L+T)^{-1}(\Lambda(., \eta())+T.) \in A(E, E)$ for any continuous function $\eta: E \rightarrow[0,1], \Lambda_{1}=F$ and $\Lambda_{0}=G$ (here $\left.\Lambda_{t}(x)=\Lambda(x, t)\right)$ and

$$
\left\{x \in E:\left(x,(L+T)^{-1}(\Phi+T)(x)\right) \cap \Lambda^{\star}(x, t) \neq \emptyset \text { for some } t \in[0,1]\right\}
$$

is compact; here $\Lambda^{\star}(x, \lambda)=\left(x,(L+T)^{-1}(\Lambda+T)(x, \lambda)\right)$.

Theorem 3.19. Let $\mathrm{E}$ be a Hausdorff topological vector space, $\mathrm{Y}$ a topological vector space, $\mathrm{U}$ an open subset of $\mathrm{E}$, $\mathrm{L}: \operatorname{dom}(\mathrm{L}) \subseteq \mathrm{E} \rightarrow \mathrm{Y}$ a linear single valued map, $\mathrm{T} \in \mathrm{H}_{\mathrm{L}}(\mathrm{E}, \mathrm{Y})$ and $\mathrm{d}$ a map defined in (3.12). Suppose there exists a map $\mathrm{H}: \mathrm{E} \times[0,1] \rightarrow 2^{\mathrm{Y}}$ with $(\mathrm{L}+\mathrm{T})^{-1}(\mathrm{H}(., \mathrm{\eta}())+.\mathrm{T}) \in \mathrm{A}(\mathrm{E}, \mathrm{E})$ for any continuous function $\eta: \mathrm{E} \rightarrow[0,1]$, $(\mathrm{L}+\mathrm{T})^{-1}(\Phi+\mathrm{T})(\mathrm{x}) \cap(\mathrm{L}+\mathrm{T})^{-1}\left(\mathrm{H}_{0}+\mathrm{T}\right)(\mathrm{x})=\emptyset$ for $\mathrm{x} \in \mathrm{E} \backslash \mathrm{U},(\mathrm{L}+\mathrm{T})^{-1}\left(\mathrm{H}_{\mathrm{t}}+\mathrm{T}\right)(\mathrm{x}) \cap(\mathrm{L}+\mathrm{T})^{-1}(\Phi+\mathrm{T})(\mathrm{x})=\emptyset$ for any $\mathrm{x} \in \partial \mathrm{U}$ and $\mathrm{t} \in[0,1]$, and

$$
\left\{x \in E:\left(x,(L+T)^{-1}(\Phi+T)(x)\right) \cap H^{\star}(x, t) \neq \emptyset \text { for some } t \in[0,1]\right\}
$$

is compact; here $\mathrm{H}^{\star}(x, \lambda)=\left(x,(\mathrm{~L}+\mathrm{T})^{-1}(\mathrm{H}+\mathrm{T})(\mathrm{x}, \lambda)\right)$. In addition assume the following hold:

$$
\left\{\begin{array}{l}
\text { for any } \mathrm{J} \in \mathrm{A}(\mathrm{E}, \mathrm{Y} ; \mathrm{L}, \mathrm{T}) \text { with } \mathrm{J}^{\star}=\mathrm{I} \times(\mathrm{L}+\mathrm{T})^{-1}(\mathrm{~J}+\mathrm{T}) \\
\text { and } \Phi \cong \mathrm{H}_{0} \text { in } \mathrm{A}(\mathrm{E}, \mathrm{Y} ; \mathrm{L}, \mathrm{T}) \text { we have that } \mathrm{d}\left(\left(\mathrm{J}^{\star}\right)^{-1}(\mathrm{~B})\right)=\mathrm{d}\left(\left(\mathrm{H}_{0}^{\star}\right)^{-1}(\mathrm{~B})\right) \neq \mathrm{d}(\emptyset),
\end{array}\right.
$$




$$
\left\{\begin{array}{l}
\left\{x \in E \backslash U:\left(x,(L+T)^{-1}(\Phi+T)(x)\right) \cap H^{\star}(x, t) \neq \emptyset \text { for some } t \in[0,1]\right\} \\
\quad \text { is closed }
\end{array}\right.
$$

and

$\{$ if $\mu: E \rightarrow[0,1]$ is any continuous map with $\mu(\overline{\mathrm{U}})=1$, then

$\left\{\left\{x \in \overline{\mathrm{U}}:\left(x,(\mathrm{~L}+\mathrm{T})^{-1}(\Phi+\mathrm{T})(\mathrm{x})\right) \cap\left(\mathrm{x},(\mathrm{L}+\mathrm{T})^{-1}\left(\mathrm{H}_{\mathrm{t} \mu(x)}+\mathrm{T}\right)(\mathrm{x})\right) \neq \emptyset\right.\right.$ for some $\left.\mathrm{t} \in[0,1]\right\}$ is closed.

Here $\mathrm{H}_{0}^{\star}=\mathrm{I} \times(\mathrm{L}+\mathrm{T})^{-1}\left(\mathrm{H}_{0}+\mathrm{T}\right)$. Let $\mathrm{H}_{1}^{\star}=\mathrm{I} \times(\mathrm{L}+\mathrm{T})^{-1}\left(\mathrm{H}_{1}+\mathrm{T}\right)$. Then we have $\mathrm{d}\left(\left(\mathrm{H}_{1}^{\star}\right)^{-1}\left(\mathrm{~B}_{\mathrm{u}}\right)\right)=$ $\mathrm{d}\left(\left(\mathrm{H}_{0}^{\star}\right)^{-1}\left(\mathrm{Bu}_{\mathrm{u}}\right)\right) \neq \mathrm{d}(\emptyset)$.

Proof. Let

$$
\mathrm{D}=\left\{x \in \mathrm{E} \backslash \mathrm{U}:\left(x,(\mathrm{~L}+\mathrm{T})^{-1}(\Phi+\mathrm{T})(\mathrm{x})\right) \cap \mathrm{H}^{\star}(x, \mathrm{t}) \neq \emptyset \text { for some } \mathrm{t} \in[0,1]\right\} .
$$

We consider two cases, as $\mathrm{D} \neq \emptyset$ and $\mathrm{D}=\emptyset$.

Case (i). $\mathrm{D}=\emptyset$.

Then for every $t \in[0,1]$ we have $\left(x,(L+T)^{-1}(\Phi+T)(x)\right) \cap H^{\star}(x, t) \neq \emptyset$. Also from $H_{1} \cong H_{0}$ in $A(E, Y ; L, T)$ and (3.13) we have

$$
\mathrm{d}\left(\left(\mathrm{H}_{1}^{\star}\right)^{-1}(\mathrm{~B})\right)=\mathrm{d}\left(\left(\mathrm{H}_{0}^{\star}\right)^{-1}(\mathrm{~B})\right) \neq \mathrm{d}(\emptyset) .
$$

Note $\left(H_{1}^{\star}\right)^{-1}(B)=\left\{x \in E:\left(x,(L+T)^{-1}(\Phi+T)(x)\right) \cap\left(x,(L+T)^{-1}\left(H_{1}+T\right)(x)\right) \neq \emptyset\right\}$. Consider $y \in E$ and $\left(y,(L+T)^{-1}(\Phi+T)(y)\right) \cap H_{1}^{\star}(y) \neq \emptyset$. Then $y \in E$ and $\Phi(y) \cap(L+T)^{-1}\left(H_{1}+T\right)(y) \neq \emptyset$. Now since $D=\emptyset$ we have $y \in U$ and $\Phi(y) \cap(L+T)^{-1}\left(H_{1}+T\right)(y) \neq \emptyset$ i.e., $y \in U$ and $\left(y,(L+T)^{-1}(\Phi+T)(y)\right) \cap H_{1}^{\star}(y) \neq \emptyset$. Consequently $\left(\mathrm{H}_{1}^{\star}\right)^{-1}(\mathrm{~B}) \subseteq\left(\mathrm{H}_{1}^{\star}\right)^{-1}\left(\mathrm{~B}_{\mathrm{U}}\right)$ and on the other hand it is immediate that $\left(\mathrm{H}_{1}^{\star}\right)^{-1}\left(\mathrm{~B}_{\mathrm{U}}\right) \subseteq$ $\left(H_{1}^{\star}\right)^{-1}(B)$. Thus $\left(H_{1}^{\star}\right)^{-1}(B)=\left(H_{1}^{\star}\right)^{-1}\left(B_{U}\right)$. It is also immediate that $\left(H_{0}^{\star}\right)^{-1}(B)=\left(H_{0}^{\star}\right)^{-1}\left(B_{u}\right)$.

Thus (3.14) implies $d\left(\left(H_{1}^{\star}\right)^{-1}\left(B_{U}\right)\right)=d\left(\left(H_{0}^{\star}\right)^{-1}\left(B_{U}\right)\right) \neq d(\emptyset)$, and we are finished.

Case (ii). $\mathrm{D} \neq \emptyset$.

Note $D$ is compact and also note $D \cap \bar{U} \neq \emptyset$. Then there exists a continuous map $\mu: E \rightarrow[0,1]$ with $\mu(D)=0$ and $\mu(\bar{U})=1$. Define a map $R: E \rightarrow 2^{Y}$ by

$$
\mathrm{R}(\mathrm{x})=\mathrm{H}(\mathrm{x}, \mu(\mathrm{x})) .
$$

Note $R \in A(E, Y ; L, T)$. In fact $R \cong H_{0}$ in $A(E, Y ; L, T)$ (to see this let $\Lambda: E \times[0,1] \rightarrow 2^{Y}$ be given by $\Lambda(x, t)=H(x, t \mu(x)))$.

Let $R^{\star}=I \times(L+T)^{-1}(R+T)$. Now (3.13) guarantees that

$$
\mathrm{d}\left(\left(\mathrm{R}^{\star}\right)^{-1}(\mathrm{~B})\right)=\mathrm{d}\left(\left(\mathrm{H}_{0}^{\star}\right)^{-1}(\mathrm{~B})\right) \neq \mathrm{d}(\emptyset) .
$$

Note $\left(R^{\star}\right)^{-1}(B)=\left\{x \in E:\left(x,(L+T)^{-1}(\Phi+T)(x)\right) \cap\left(x,(L+T)^{-1}(R+T)(x)\right) \neq \emptyset\right\}$. Consider $x \in E$ and $\left(x,(L+T)^{-1}(\Phi+T)(x)\right) \cap R^{\star}(x) \neq \emptyset$. Then $x \in E$ and $\emptyset \neq(L+T)^{-1}(\Phi+T)(x) \cap(L+T)^{-1}(R+T)(x)=$ $(L+T)^{-1}(\Phi+T)(x) \cap(L+T)^{-1}\left(H_{\mu(x)}+T\right)(x)$. If $x \in E \backslash U$ then since $x \in D$ we have $\emptyset \neq(L+T)^{-1}(\Phi+$ $\mathrm{T})(\mathrm{x}) \cap(\mathrm{L}+\mathrm{T})^{-1}\left(\mathrm{H}_{\mu(\mathrm{x})}+\mathrm{T}\right)(\mathrm{x})=(\mathrm{L}+\mathrm{T})^{-1}(\Phi+\mathrm{T})(\mathrm{x}) \cap(\mathrm{L}+\mathrm{T})^{-1}\left(\mathrm{H}_{0}+\mathrm{T}\right)(\mathrm{x})$ which is a contradiction. Thus $x \in U$ and $\emptyset \neq(L+T)^{-1}(\Phi+T)(x) \cap(L+T)^{-1}(R+T)(x)$. Consequently $\left(R^{\star}\right)^{-1}(B) \subseteq\left(R^{\star}\right)^{-1}\left(B_{U}\right)$ and on the other hand it is immediate that $\left(R^{\star}\right)^{-1}(B u) \subseteq\left(R^{\star}\right)^{-1}(B)$. Thus $\left(R^{\star}\right)^{-1}(B)=\left(R^{\star}\right)^{-1}(B u)$. Also $\left(\mathrm{H}_{0}^{\star}\right)^{-1}(\mathrm{~B})=\left(\mathrm{H}_{0}^{\star}\right)^{-1}\left(\mathrm{~B}_{\mathrm{u}}\right)$. Thus (3.15) implies

$$
\mathrm{d}\left(\left(\mathrm{R}^{\star}\right)^{-1}\left(\mathrm{~B}_{\mathrm{U}}\right)\right)=\mathrm{d}\left(\left(\mathrm{H}_{0}^{\star}\right)^{-1}\left(\mathrm{~B}_{\mathrm{u}}\right)\right) \neq \mathrm{d}(\emptyset) .
$$


Finally notice

$$
\begin{aligned}
\left(R^{\star}\right)^{-1}(B u) & =\left\{x \in U:\left(x,(L+T)^{-1}(\Phi+T)(x)\right) \cap\left(x,(L+T)^{-1}\left(H_{\mu(x)}+T\right)(x)\right) \neq \emptyset\right\} \\
& =\left\{x \in U:\left(x,(L+T)^{-1}(\Phi+T)(x)\right) \cap\left(x,(L+T)^{-1}\left(H_{1}+T\right)(x)\right) \neq \emptyset\right\}=\left(H_{1}^{\star}\right)^{-1}(B u),
\end{aligned}
$$

so from (3.16) we have $\mathrm{d}\left(\left(\mathrm{H}_{1}^{\star}\right)^{-1}\left(\mathrm{~B}_{\mathrm{u}}\right)\right)=\mathrm{d}\left(\left(\mathrm{H}_{0}^{\star}\right)^{-1}\left(\mathrm{~B}_{\mathrm{u}}\right)\right) \neq \mathrm{d}(\emptyset)$.

Remark 3.20. In Definition 3.18 and in the statement of Theorem 3.19 we could replace, any continuous map $\eta: E \rightarrow[0,1]$, with, any continuous map $\eta: E \rightarrow[0,1]$ with $\eta(\bar{U})=1$.

Remark 3.21. There is an analogue of Remark 3.16 (for normal topological vector spaces) in the statement of Theorem 3.19 and in Definition 3.18.

\section{Acknowledgment}

The authors extend their appreciation to the International Scientific Partnership Program ISPP at King Saud University for funding this research work through ISPP No. 0027.

\section{References}

[1] L. Górniewicz, Topological fixed point theory of multivalued mappings, Kluwer Academic Publishers, Dordrecht, (1999). 1

[2] A. Granas, J. Dugundji, Fixed Point Theory, Springer-Verlag, New York, (2003). 1

[3] D. O'Regan, Generalized Leray-Schauder principles for general classes of maps in completely regular topological spaces, Appl. Anal., 93 (2014), 1674-1690. 1

[4] D. O'Regan, Abstract Leray-Schauder type alternatives and extensions, Analele Stiintifice ale Universitatii Ovidius Constanta, Serie Matematica, to appear.

[5] D. O'Regan, R. Precup, Theorems of Leray-Schauder Type and Applications, Gordon and Breach Science Publishers, Amsterdam, (2001) 1 